\title{
A systematic literature review of how and whether social media data can complement traditional survey data to study public opinion
}

\author{
Maud Reveilhac $^{1}$ (D) Stephanie Steinmetz ${ }^{1}$ (D) $\cdot$ Davide Morselli $^{1,2}$ (D)
}

Received: 7 April 2021 / Revised: 4 July 2021 / Accepted: 3 January 2022 /

Published online: 14 February 2022

(C) The Author(s) 2022

\begin{abstract}
In this article, we review existing research on the complementarity of social media data and survey data for the study of public opinion. We start by situating our review in the extensive literature $(\mathrm{N}=187)$ about the uses, challenges, and frameworks related to the use of social media for studying public opinion. Based on 187 relevant articles (141 empirical and 46 theoretical) - we identify within the 141 empircal ones six main research approaches concerning the complementarity of both data sources. Results show that the biggest share of the research has focused on how social media can be used to confirm survey findings, especially for election predictions. The main contribution of our review is to detail and classify other growing complementarity approaches, such as comparing both data sources on a given phenomenon, using survey measures as a proxy in social media research, enriching surveys with SMD, recruiting individuals on social media to conduct a second survey phase, and generating new insight on "old" or "under-investigated" topics or theories using SMD. We discuss the advantages and disadvantages associated with each of these approaches in relation to four main research purposes, namely the improvement of validity, sustainability, reliability, and interpretability. We conclude by discussing some limitations of our study and highlighting future paths for research.
\end{abstract}

Keywords Social media $\cdot$ Survey data $\cdot$ Data complementarity $\cdot$ Public opinion

Maud Reveilhac

maud.reveilhac@unil.ch

Stephanie Steinmetz

stephanie.steinmetz@unil.ch

Davide Morselli

davide.morselli@unil.ch

1 Lausanne University (Switzerland), Faculty of Social and Political Sciences, Institute of Social Sciences, Life Course and Social Inequality Research Centre, Lausanne, Switzerland

2 Swiss Centre of Expertise in Life Course Research LIVES, Lausanne, Switzerland 


\section{Introduction}

This paper provides a systematic literature review of how social media data (SMD) and traditional survey data have been used complementarily to study public opinion (PO) over the last decade. As social media users represent more than half of the world's population (see [26]) and provide continuous reactions to daily socio-political events, it is not surprising that traditional survey research has been concerned about whether such data would make surveys obsolete or whether they could be used complementarily. Addressing these questions is particularly relevant in the area of PO. Social media plays a growing role in the formation of $\mathrm{PO}$ as user-generated content on these platforms is increasingly deployed as representations of PO (e.g. [27, 56]). In addition, politicians increasingly consider social media, especially Twitter, to be a "barometer" of PO [44].

Despite the extensive literature about the benefits and challenges of using SMD to answer social and political questions, as well as about SMD as a possible replacement for traditional surveys, a comprehensive overview of the complementarity of both data sources remains limited. The aim of this paper is to fill this gap by providing a systematic literature review focusing on how SMD and survey data can complement each other to study PO. Inspired by the influential study of Japec et al. [45] which elaborated on the complementarity of survey data and "big data" (rather broadly defined), we want to concentrate, however, on one type of "big data", namely SMD. There are two main reasons for this choice. First, SMD are a specific type of "non-survey" data which possess specific arrangements (or conventions) and paradata that are different from other types of administrative or "big data", especially when it come to the assessment of PO. Second, whereas there is substantial research on augmenting survey data with administrative (e.g. electricity or water consumption) or other type of "web data" (e.g. Google searches or citation metrics) to improve estimates of PO or official statistics, we still lack an overarching picture of the (new) developments and approaches of complementing SMD and surveys with each other.

Our analysis is based on an extensive survey of the literature capturing a representative sample of the best published theoretical and empirical scientific papers on the topic $(\mathrm{N}=187)$. We have restricted the analytical period to the last decade (2010-2020) as the discussion on complementarity is still a young field of study (e.g. [58]). On this basis, we have been able to identify six complementarity approaches which can be synthesised to four major purposes, namely predicting, substituting, comparing, and linking SMD and survey data.

In the next section, we situate our review within the existing literature by demonstrating how the scientific discussion surrounding the opportunities and challenges offered by SMD within survey research has evolved, especially by highlighting the complementary understanding of PO offered by both data sources. Then, we discuss more specifically which research approaches have emerged, and we classify them according to four main research purposes using both data sources complementarily. The analysis of the empirical studies aims to act as a guide for other researchers by identifying research gaps and highlighting the pros and cons of each approach. Furthermore, we underline areas for future improvements and point to technical and ethical considerations. We conclude by mentioning the main contributions and limitations of our review.

\section{Background - The complementary understandings of PO}

Surveys have long been the most predictive and accurate tools for collecting and measuring opinion. However, over the last decade, decreasing response rates have called into question the 
potential of using a random sample of individuals to represent an entire population (e.g. [37, 49]), thus posing important concerns about the sustainability of survey research. Even by adapting to new modes, such as push-to-web, to increase response rates, it remains unclear whether surveys will maintain this dominant role as communication habits continue to change (e.g. [68]). Given the recent "survey crisis" (e.g. [13, 22]), an increasingly rich source of PO data is commonly referred to as "big data". These "new" data take the form of extraordinarily large and complex datasets. There are three attributes that are generally agreed upon to describe this type of data (e.g. [19]), namely volume, velocity, and variety. Social media are a sub-type of big data where people express their thoughts and opinions with the purpose of sharing them with others [18]. Due to their inherent properties, SMD have been seen as a promising complementary, and even alternative, source of data for exploring PO. However, researchers acknowledged early on that, almost universally, SMD are non-random, and thus discouraged using them as a means of making generalisable claims. This challenge is well highlighted by Schober et al. [68], who claim that, while the social media researcher seeks to achieve topic coverage, the survey researcher emphasises population coverage as a central endeavour.

An entire strand of research thus focussed on how surveys and social media differ in several aspects. Table 1 attempts to classify the most prominent differences along which SMD and survey data are typically compared. We have identified several dimensions based on recurring criteria mentioned in the literature concerning the nature of and the relationship between both data sources. Often-cited criteria include the type of population and data signal, the unit of observation and analysis, and the available meta-data (for a thorough discussion of the differences see [18, 68], and [77]).

To understand how to best use both data sources complementarily, it is also essential to reflect on how they construct PO differently. This is increasingly important, as what constitutes "the public" tends to be forged by the methods and data from which it is derived [56]. In

Table 1 Differences between SMD and survey data to study PO

\begin{tabular}{|c|c|c|}
\hline & SM & Survey \\
\hline Type of population & Selective & Representative \\
\hline Data signals & $\begin{array}{l}\text { Platform users and their signals (e.g. posts } \\
\text { or tweets, \#hashtags, @ mentions, } \\
\text { retweets, replies) }\end{array}$ & $\begin{array}{l}\text { Opinion survey of individuals with a } \\
\text { defined sampling frame }\end{array}$ \\
\hline Types of data & $\begin{array}{l}\text { Unstructured texts containing opinions and } \\
\text { opinion strength or merely information } \\
\text { (e.g. links) }\end{array}$ & $\begin{array}{l}\text { Structured opinions measured by answers } \\
\text { to pre-defined and pre-tested survey } \\
\text { questions (scales) }\end{array}$ \\
\hline $\begin{array}{l}\text { Unit of observation or } \\
\text { the level at which } \\
\text { data are collected }\end{array}$ & $\begin{array}{l}\text { Can be any of the following: users, search } \\
\text { queries or keywords, \#hashtags or } \\
@ \text { mentions, retweets, or replies, likes or } \\
\text { emotional reactions, location }\end{array}$ & $\begin{array}{l}\text { Individuals from a sampling frame } \\
\text { representing a target population }\end{array}$ \\
\hline $\begin{array}{l}\text { Unit of analysis or } \\
\text { level at which the } \\
\text { data are analysed }\end{array}$ & $\begin{array}{l}\text { Can be any of the following: users, } \\
\text { location, texts from a specific topic or } \\
\text { sentiment, overall texts, links, or other } \\
\text { metadata }\end{array}$ & $\begin{array}{l}\text { Individuals' responses to survey items or } \\
\text { aggregated responses at the country, } \\
\text { region or household level }\end{array}$ \\
\hline Meta-data & $\begin{array}{l}\text { Set of users' behavioural information (e.g. } \\
\text { network, frequency of use, interactions) } \\
\text { and contextual information (e.g. time } \\
\text { and location) }\end{array}$ & $\begin{array}{l}\text { Precise and quasi-complete socio-- } \\
\text { demographic information on individ- } \\
\text { uals and auxiliary data (e.g. number of } \\
\text { contact attempts, number of persons in } \\
\text { the household) }\end{array}$ \\
\hline
\end{tabular}


survey research, PO is equivalent to the private opinion of a representative public, operationalised as a set of positions on a given topic. PO can thus be conceptualised as a reflection of a shared position among citizens on specific issues that are then amplified and reviewed by news media and political actors [42]. Survey measures of PO are constrained by the scope of the questionnaires, which usually provide little room for spontaneous expressions of opinion (except in open-ended survey questions). The diversity of opinions is thereby reduced into a set of discrete and aggregate data (e.g. [75]). Conversely, the reliance on social media for measuring PO expands the societal and collective components of opinions [59] by conceptualising it in Habermas' [39] terms as a complex system of representations. In this respect, SMD are better suited to capturing the conversational and relational nature of PO formation [3]. Hence, where survey data weigh precision and standardisation, SMD excel in multidimensionality and polyphony. In addition to their focus on solicited private opinions, surveys are also less reactive to opinion changes than SMD. In theory, opinion changes could be assessed by frequent short opinion surveys (e.g. every two months). However, the advantage of SMD is that they can cover opinion change more rapidly (and on an ad hoc basis), thus reacting faster to events, which is almost impossible for surveys (e.g. it takes more time to set up probability-based surveys for the study of COVID compared to what can be done with SMD).

Despite the advantages offered by social media for measuring more social and timelier opinions, the reliance on SMD raises important questions for empirical research on (automated) measurements of opinions and on the choice of the indicators employed to model opinions. Indeed, constructing measures of PO based on SMD can be very time consuming and can involve a lot of pre-processing effort before the data can be translated into meaningful measures of expressed opinions. Furthermore, it sometimes remains quite difficult to know what is driving the evolution of ideas and concerns found in online conversations. Consequently, a current strand of research seeks to better understand the issues of representativeness of social media communities and the validity of measured opinion, especially opinions stemming from sentiment analysis. While there is a rising interest in applying SMD to understand opinion, and even to replace traditional surveys (e.g. [3, 32]), SMD alone are of limited use for social scientific research as they usually provide incomplete and imprecise information. However, the issues associated with SMD are not necessarily fatal to the proposition that they can be used to generate social insights, especially in complementing survey data. An efficient strategy to enhance research lies, therefore, in the analysis of how both data sources can complement each other in ways that maximise their strengths.

In the next sections, we aim to show that there is a plethora of research practices in which both data sources complement each other for the study of PO. To date, however, there is still no consensus about the best way to use SMD for studying PO [58]. We are now at a point where we should reflect on what has been done so far, what lessons we can learn from it, and then specify suitable trends for social research. In this paper, we seek to fill this gap by reviewing research that uses both data sources complementarily for the purposes of measuring $\mathrm{PO}$ and by providing a critical evaluation of the identified research paths.

\section{Method of analysis: Building a corpus of relevant articles}

To build our corpus of scientific articles, we carried out several searches in bibliographic databases (focusing on Scopus and Google Scholar) using the software PublishOrPerish [40]. 
We obtained an initial corpus of 3596 unique papers, which we reduced to papers that were relevant for the scope of our review. The initial corpus was deliberately based on a searchquery that was broad enough to collect the relevant literature, while not missing important papers. We used the query "(social media OR twitter OR facebook OR instagram OR reddit) AND (survey OR surveys OR polls)" and specified that it should appear in the body of the text (using the keyword field) instead of appearing only in the title or abstract, which were found to be too restrictive to capture the literature of interest. The query was designed to restrict the focus of our review to SMD, thus ignoring other types of "big data" or "digital trace" data.

A first filter was applied to reduce the number of papers to journal articles, book chapters, and scientific reports (thus excluding books, theses, and conference papers) as we wanted to concentrate on high-valued scientific sources which have already been approved by the scientific community. In this respect, including conference papers would have drastically inflated the number of (duplicated) papers concerned with predictions and with replicating previous studies using alternative methods of analysis and algorithms. Among the remaining papers, we applied two eligibility criteria to disregard those that were not pertinent to the analysis as i) their focus was not on PO, ii) they were oriented towards a specific aspect of data treatment (e.g. estimating socio-demographics from texts or profile pictures) or an analytical strategy (e.g. elaborating algorithms). We also excluded articles mentioning survey findings without an explicit aim of supplementing, comparing, or combining those with SMD.

\section{Results of the literature review on the uses of social media as a complement to surveys}

Overall, the collection protocol left us with 187 papers - 141 of an empirical and 46 of a theoretical nature (these papers can be found in the Appendix). Most of these papers stem from political communication and computational social sciences journals. Although the sample of 187 papers may not cover the whole corpus of research on the subject, it is nonetheless sufficient to highlight the main research directions that have been endorsed on the topic of complementarity. Figure 1 provides an overview of the yearly repartition of the retrieved papers differentiating between those with a theoretical $(\mathrm{N}=46)$ and an empirical $(\mathrm{N}=141)$ focus. While the number of theoretical papers remains stable over the years, we can see a steady increase in empirical papers over time.

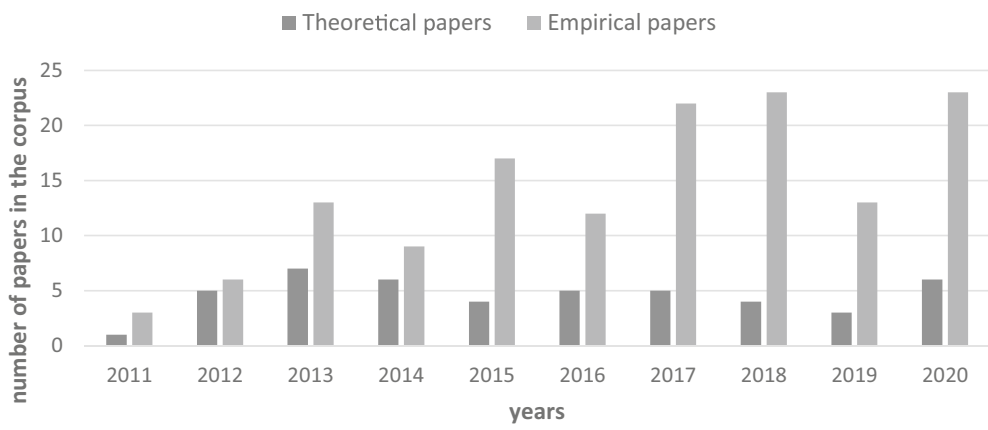

Fig. 1 Number of empirical and theoretical articles according to our meta-review of the existing literature using surveys and SMD 


\subsection{Theoretical insights}

Starting with the theoretical papers in our review ( $\mathrm{N}=46$, see Table 2 in the Appendix), survey and social media researchers have explored ways in which social media and survey data can yield congruent conclusions (e.g. [68]). One part of these articles $(n=14)$ tries to establish a framework regarding the predictive power of SMD as a potential substitute for surveys. This line of research stems principally from the fields of election and economy forecasting (for recent reviews see $[15,66])$.

Another strand of theoretical articles $(n=14)$ focuses instead on the compliance of social media research with established reporting standards so as to guarantee transparency and replicability (e.g. [51]). Finding ways of integrating data obtained from different sources (n = 3) also constitutes a fertile path of research [46]. In this respect, Stier et al. [72] provide the most advanced guide on how to systematically link survey data with information from external data sources, including SMD, at different level of analysis. The authors demonstrate that integrating traditional survey data and digital trace data is of growing interest, notably because of the limited reliability of self-reported behavioural measures and declining response rates. Additionally, enriching survey data with SMD could also help to reduce unit non-response and to control for the unrepresentativeness of SMD, as they are limited to those respondents having social media profiles and consenting to the linkage. Finally, a smaller share of research $(n=5)$ focuses on developing a quality assessment framework for SMD which is similar to the Total Survey Error (TSE) [11, 38]. The TSE framework has been extended to encompass SMD and their inherent quality challenges (see the studies by Sen et al. [70] on Twitter-based studies and Jungherr [47] for a measurement theory to account for the pitfalls of digital traces). In a similar vein, Hsieh and Murphy [43] analysed the potential benefits of evaluating estimates from surveys and SMD in common terms and arrived at a general error framework for Twitter opinion research. Olteanu et al. [61] went a step further by pointing to the errors and biases that could potentially affect studies based on digital behavioural data, outlining them in an idealised study framework. The paper by Sen et al. [70] provides the most advanced framework to date. It involves potential measurement and representation errors in a digital trace-based study lifecycle where they are classified according to their sources.

Other research $(n=5)$ tackles the ontology of SMD as compared to survey data. In these papers, prevalent discussions revolve around the conception of opinion as measured by both data sources, as well as debates related to the evolution of "new" research "paradigms" or "digital hermeneutics". The remaining papers concentrate on behavioural research $(\mathrm{n}=2)$, demographic research $(n=2)$, and small data analysis in political communication $(n=1)$.

Overall, the considered theoretical articles stress the importance of developing a framework that accounts for possible biases of SMD while remaining in, or mirroring, the TSE. Moreover, they also emphasize the need, in this debate, to focus on the complementarity rather than the replacing aspect, notably by developing clear and reliable linking strategies. These articles also encourage researchers to go beyond the dominant model for understanding PO from probability sample surveys to encompass other ("new") expressions of opinions (e.g. Murphy et al. 2014) that can possibly supplement or even replace survey-based approaches.

\subsection{Empirical insights}

The empirical literature $(\mathrm{N}=141)$ focuses on a rather narrow set of topics, such as elections, political issues, and approval ratings for the presidency (64\%). Another important area of PO 
research using SMD complementarily with survey data is related to health (e.g. vaccination, drugs, etc.), equality issues, and climate or environment-related concerns. Most empirical studies in our review are based on Twitter data (73\%), followed by Facebook (18\%) and other social media (9\%). This is related to the fact that not all social media platforms provide the same degree of data accessibility [8]. For instance, Facebook imposes severe limitations on the scope of retrievable data, whereas Twitter has less strong privacy settings, allowing researchers to get access to Twitter's historical data.

Overall, we derived six major approaches on how survey data and SMD can complement each other namely i) predicting social and political outcomes using SMD ( $n=48)$, ii) comparing both data sources on a given phenomenon $(n=26)$, iii) using survey measures as a proxy in social media research $(n=18)$, iv) enriching surveys with $\operatorname{SMD}(n=9)$, v) recruiting individuals on social media to conduct a second survey phase $(n=8)$, and vi) generating new insight on "old" or "under-investigated" topics or theories using SMD $(n=32)$. These approaches can be synthesised in four, partly overlapping, 'data complementing' research purposes: i) validating survey findings with SMD, ii) improving the sustainability of the research by diversifying the views on a phenomenon, iii) improving the reliability of survey measures by specifying measurements, and iv) improving the interpretability of social or political issues. Figure 2 summarises the relationship between the six approaches and the four research purposes. Furthermore, it shows that each purpose leads to a typical way of using both data sources complementarily. For instance, improving reliability by specifying a research question involves data linkage strategies, while generating new insights involves a sequential use of social media and survey stages.

The analysis of our corpus suggests that the biggest part of research concentrates on whether SMD can potentially substitute survey data $(n=48$, see Table 3 in the Appendix). This has mostly been done by trying to replicate survey findings by using SMD for forecasting (see recent review by [66]). The aim to predict real-world outcomes with SMD in the realm of PO has essentially been applied to elections. Most of these papers directly refer to the muchcited study of O'Connor et al. [60] which purpose is to validate SMD against survey findings. While research in this area has tested a range of different methodologies, the results remain inconclusive, and only in some cases could elections be accurately predicted (e.g. [31, 47]). Recent literature reviews on the use of SMD for running electoral predictions (e.g. [15]) classify studies according to the employed methods of prediction, such as volume, sentiment, or network approaches. These reviews show considerable variance in the accuracy of predictions, which, on average, lag behind the established survey measurements. A common

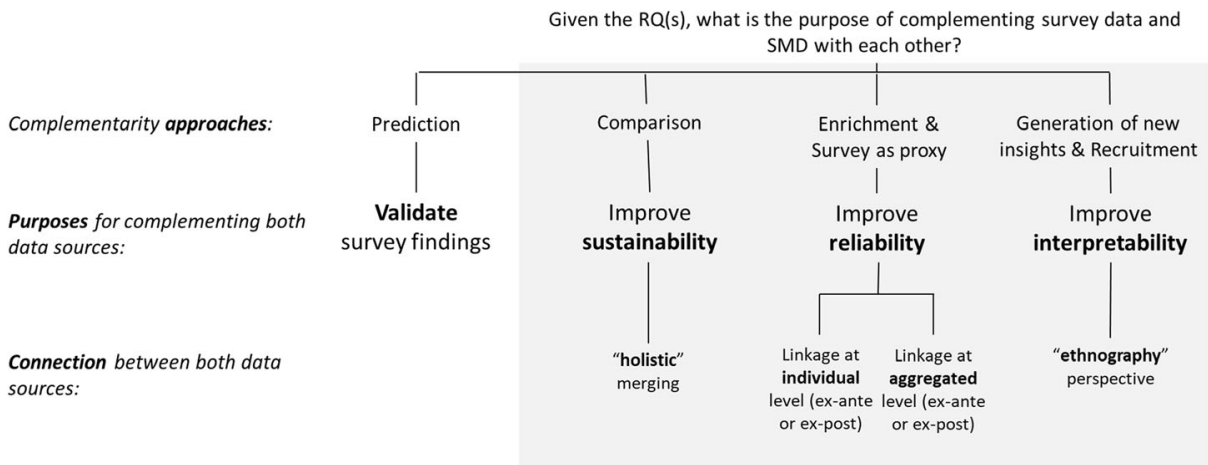

Fig. 2 Complementary approaches using SMD and survey data for the study of PO 
problem of the aforementioned studies lies in the decision about which approach can most accurately yield predictions (but also which social media platforms are better suited, and how that varies in different geographical or temporal contexts). This inference problem is quite complex as various elements are involved in skewing the samples in social media debates. To date, the inconclusive state of the research has led to a research agenda aiming to respond to the plea from Gayo-Avello et al. [33] for a "model explaining the predictive power of social media" (p. 490). In this realm, for instance, the study of Pasek et al. (2019) assesses how patterns of approval among population subgroups compare to tweets about the president, while disentangling effects at the individual and group levels of analysis. On a more theoretical level, the study by Schober et al. [69] seeks to elaborate when and under what conditions SMD can be used to make valid inferences. However, the inconclusive state of the research may also be linked to the fact that predictions are often done based on the content created by users and overlook the characteristics of the creating users. For instance, SMD can be biased towards a particular group (see [5, 24]). Moreover, interactions on social media platforms are not always the product of individuals, but also bots, organisations, political parties, etc. [80]. Based on the evaluation of the body of articles falling under the 'substitution paradigm', a path for future research could be to better account for the characteristics of social media users, insofar as these characteristics can be useful for assessing how individual tweets can be converted into meaningful measures of expressed opinion. To do so, future studies could survey social media users identified using relevant key terms (e.g. hashtags or mentions) to gauge the relationship between social media measures of their sentiment and survey measures of their attitudes.

The second dominant approach in our review is related to how surveys can be enriched with SMD ( $\mathrm{n}=9$, see Table 4 in the Appendix). Here, SMD are collected with the intention of improving the reliability of survey measures at the individual or aggregate level. Replication of survey-based opinions can be difficult, either because of improper interpretation of the findings or because insufficient information has been provided. Such issues undermine the credibility of survey research and make it difficult to evaluate the contributions of a given study. Research aiming to enrich surveys with SMD most often implies the adoption of a data-linking strategy. This can be done, for instance, either at the user level, public actor level, geographic level, or temporal level (see [72]). Enriching surveys with SMD can serve several goals. First, it can help to augment the explanatory potential of survey measures. For instance, De Sio \& Weber [23] adopted an innovative research design to explain election outcomes based on party strategy on social media with respect to policy issue salience. They did this by linking representative mass surveys from six European countries with Twitter analysis of campaign activity. Second, enrichment of survey data with SMD can also help to test research hypotheses by relying on "true" behavioural measures (instead of self-reported survey measures). For instance, Karlsen and Enjolras [48] linked candidate survey data with Twitter data to study styles of social media campaigning. These differences in campaigning styles were then related to the extent to which candidates were successful on Twitter. Third, SMD also offer an opportunity to address issues of item non-response and calibration of novel measures. For instance, Shin [71] studied the extent to which social media users selectively consumed likeminded news stories by linking survey responses from Twitter users with their media following and exposure to news via their friends. The study further showed some differences between self-reports and digital measures, such as more pronounced patterns of selective exposure in the SMD. Finally, linking social survey and SMD further provides an opportunity to explore the relationship between attitudes and beliefs reported through surveys and content (and behaviours) generated online. For instance, Cardenal et al. [14] combined survey and 
Web-tracking data to analyse how Facebook-referred news consumption influenced social media users' agendas. They found that selective exposure increased with amplified news consumption. The core problem in these studies lies in gaining consent to carry out the data linkage. This constitutes a complex procedure in which issues of anonymity, security, and disclosure all come to the fore. An additional problem is that social media measurements provide only one partial view of opinions. For instance, while researchers can measure how many times a given message has been liked, shared, or retweeted, it is much harder to account for (or measure) how often a given message has been seen or has attracted attention. Moreover, our corpus shows that research relying on linking strategies tends to remain at the individual and public actor levels of analysis, which requires requesting consent to use the linked data. This may, in turn, introduce consent or selection bias. To mitigate such difficulties, future studies should also explore the potentials of linking both data sources at higher levels of analysis, such as country or according to topicality level.

A third purpose is to use surveys as a proxy in social media research. This approach therefore reverses the logic that SMD are always used as a complementary (side) element of the main survey-based analyses. In this kind of "survey proxy approach" ( $n=18$, see Table 5 in the Appendix), SMD are used as the main source of analysis, while the survey data are used for contextualising or calibrating SMD. A first strand of research relies on SMD to complement traditional research approaches in political communication and citizens' political engagement. For instance, the assessment of the importance of given public concerns in PO has been measured extensively with the "most important problem" survey item. Social media provide another way to measure this concern in an unintrusive way by (semi-)automatically classifying the content of social media texts, while also accounting for the extent to which different actors are responsive to these concerns. Following this logic, the study conducted by Eberl et al. [28] investigated the effects of sentiment and issue salience on emotionally labelled responses to posts written by political actors on Facebook. Another study, by Plescia et al. [64], analysed the responsiveness of populist parties to the issue salience amongst the public. They did this by relying on survey data to measure public salience and tweets to assess salience issue for parties. A second strand of studies aims at facilitating cross-national comparisons. For instance, a possible application consists in using survey data for classifying parties and voters along important dimensions (e.g. see [30]). Here, parties were placed on a left and right spectrum using the Chapel Hill Expert Survey [4]. Party score on the overall ideological stance was then used as an explanatory variable in subsequent analysis. Another example is the study by Park et al. [62] which investigated the consumption of popular YouTube videos in countries that differ in cultural values, language, gross domestic product, and Internet penetration rate. A possible issue encountered by these studies is linked to spurious effects between survey and social media measurements (e.g. misleading or unexplained correlations). Furthermore, these studies tend to remain poorly equipped to explain actual motives behind social media users' expression of opinions or reactions. The "survey as proxy" approach requires a considerable dose of ingenuity and methodological innovation to mine social media for producing opinion estimates that can be merged with survey estimates. For instance, SMD corpora often deviate from a predefined (survey) coding scheme. Substantively, a future path of research should take advantage of the fact that a growing number of societal issues have become transnational, such as immigration, terrorism, women's rights, and climate change. Such research could involve the combination of word embeddings and survey opinion measures at the country level.

A fourth approach aims to compare SMD with survey responses that directly measure PO. Studies comparing SMD with survey data $(n=26$, see Table 6 in Appendix) essentially aim at 
improving sustainability of the research, which consists in the ability to gauge PO consistently over time. Sustainability thus implies that we should develop designs that include opportunities for "holistic merging" of the data that will generate more inclusive and fine-grained research insights. There are several reasons that comparing both data sources is meaningful for social research. Firstly, comparing SMD and survey data can be very useful in times of protests and collective actions, notably due to the difficulty of generating survey data to properly assess these disruptive changes (see critique of survey data by Lee [53]). The timing of an event might indeed not coincide with the timing of a survey, which is often done ex-post. For instance, Davis et al. [21] examined the extent to which tweets about the affordable care act ("Obamacare") could be used to measure PO over time. Secondly, social media can be compared to surveys for research questions that require chronicity, on a weekly or daily basis, thus going beyond the few ongoing surveys that collect data monthly or yearly. For instance, Diaz et al. [25] demonstrated how social media activity functions like an "opt-in panel" where users repeatedly discuss the same topics. This allows us to study, longitudinally, quite rapid shifts in individual opinions and behaviours, thus complementing survey panels which are prohibitively expensive. Another example is the study by Loureiro \& Alló [54], which aimed to complement surveys by providing up-to-date measurements about social concerns when debating mitigation and energy transition paths. Thirdly, survey questions are often designed to capture internal attitudes toward a specific object. However, the relevance of certain survey questions might vary over time and, in some cases, might no longer correspond to the issues discussed spontaneously online. For instance, at a geographical level, the study by Scarborough [67] compared gender equality attitudes found in survey data to sentiments emanating from tweets. Fourth, SMD can produce quicker and less expensive statistics for enabling informed policy and program decisions. However, this requires gaining knowledge of where any possible disparities in attitude distributions between SMD and survey data may lie. In this respect, the study by Amaya et al. [2] presented recent advancements. The authors compared attitude distributions between Reddit users and survey measures of political leaning, political interest, and policy issues. They showed that Reddit users tend to have more centrist and normally distributed scores than the survey data, skewing estimates toward the conservative end of the spectrum on all attitude measures. Another study, from Pasek et al. (2020), explained that SMD might be better conceived as providing insights about public attention rather than ("survey like") attitudes or opinions. To do so, the authors compared tweets mentioning the presidential candidates and open-ended survey questions about the candidates to assess whether spikes surrounding political events correlate between both data sources. Results display some support for the correlation between social media attention and survey data, but they also show systematic differences that need to be better understood to assess when SMD can best generate insights about select topics. The research comparing both data sources tends to remain focused on volume analysis and tonality assessment. This type of research also tends to pay little attention to the domain-specificity of the SMD collected as well as to ways of mitigating replicability and consistency issues (e.g. [34]). For instance, the evolution of search queries around a given theme might lack precision and consistency over time. The connotation of hashtags can change or whole hashtags can even disappear. Better combining both data sources also requires elaborating more sophisticated measures of opinion and attitudes. One could think about pushing forward "stance detection" in complement to "sentiment detection", but also about advancing "narrative analysis" in complement to "topic or frame detection". These are avenues where computational social research would benefit from the expertise of applied computational linguistics. 
A fifth approach implicates using SMD to generate new insights. This is especially useful when survey data are not available or when survey data are not recent enough $(n=32$, see Table 7 in Appendix). Here, the main purpose is to improve the interpretability of the research by adopting an "ethnographic" methodology. By avoiding rigid research design plans, SMD can remain responsive to, and pursue, new paths of discovery as they emerge. Based on the papers collected, we found typical reasons for relying on SMD to generate new insights, such as capturing emergent opinions, expanding the scope of survey measures, validating survey measures, proposing novel approaches to get a more nuanced or dynamic perspective on PO, and making causal analyses (see column "Reason to complement" in Table 6 in Appendix). When used for capturing emergent opinions, SMD allow us to study the topical and normative climate around specific issues for which we have no theoretically grounded ideas yet. In this exploratory design, social media can provide survey researchers with a snapshot of important societal and political concerns worth surveying in future research. This is especially useful for emerging topics, such as nuclear power (e.g. [50]) or health-related policies [65, 74]. On these emerging issues, SMD can be used in an exploratory or ethnographic perspective to generate initial and qualitative insights into under-studied research objects in order to develop quantitative survey measurements. SMD can also be useful for expanding the scope of survey measures on topics that are difficult to survey. For instance, Hatipoğlu et al. [41] used SMD to study international relationships with a case study on Turkish sentiments towards Syrian refugees using Twitter. Another study by Guan et al. (2020) relied on the social media platform Weibo to study Chinese views of the United States. SMD can also be useful for validating survey measures. For instance, the study by Dahlberg et al. [20] investigated the meanings of democracy in a cross-country perspective to better understand differences in the usage of the term "democracy" across languages and countries. The authors' findings aimed to inform survey measurements about the different conceptualisations of democracy, notably by highlighting translations and language equivalence issues in survey items. Another reason is to propose novel approaches for achieving a more nuanced or dynamic perspective on PO. For instance, researchers can add new components and improve "old findings", which are difficult to measure with survey data. In this view, the study by Barberá et al. [7] modelled policy issue responsiveness using Twitter data, thus going beyond the more static perspective on issue congruence offered by surveys. In another study, Clark et al. [16] investigated organisational legitimacy in a case study about public reactions on social media to the Supreme Court's samesex marriage cases. The authors argued that SMD can lessen some of the limitations of survey research in the field, notably by accessing not just policy positioning among individuals but also a variety of features of political discourse, such as opinion intensity and emotions like anger or happiness. SMD can also be used to make causal inferences in order to understand changes in opinion before and after an event, such as measuring the effect of a promulgated law on PO [1]. Here, SMD allow researchers to rely on spontaneous opinions expressed online rather than on retrospective survey questions, and this can help develop policy initiatives. For instance, Tavoschi et al. [73] used Twitter as a "sentinel system" to assess the orientation of PO in relation to vaccination. Despite the advantages of SMD in providing new research insights, these studies tend to lack a rigorous contextualisation of the findings derived from SMD. In this respect, a reliance on SMD would benefit from implementing sequential designs, where social media help to identify specific populations or sub-topics, which could then lead to a second quantitative survey phase. Whenever possible, SMD would further benefit from a comparison with longitudinal surveys to assess the extent to which both data sources reveal similar dynamics of change. Future studies could further exploit SMD's ability to generate 
new insights for research in sensitive fields, such as war, racism, sexual orientation, and religious beliefs. These are often topics on which it remains difficult to collect survey data, notably because of the social desirability bias (e.g. [52]) and the like (e.g. extreme response style, moderacy bias, and acquiescence), but also because of the fear of being denounced or because the topic is controversial.

The last approach using SMD and survey data complementarily focuses on using social media to recruit survey respondents. However, in comparison with the previous approach, the studies collected here usually analyse SMD and survey data in sequential phases. As we only consider papers that are in some way also related to PO and are not solely about recruitment of survey respondents and their socio-demographic characteristics, the number of studies we were able to analyse is much smaller ( $n=8$, see Table 8 in the Appendix). Our review demonstrates that the papers essentially tackle the problem surveys have in recruiting specific politically involved sub-groups of the population. In particular, the research relies on social media to access representative samples of social media users, for instance, those who commented on their countries' elections (see [9, 12]) or who posted at least one election-related tweet [79]. Furthermore, in these studies, ethical concerns (e.g. privacy, tracking, etc.), but also the technical affordability of the social media platform used, are discussed. The latter issue is important, as each social media platform has particular arrangements which are likely to influence the group of individuals that can be reached. Overall, future studies could think about extending the recruitment approach to enhance our knowledge of reactions to systematic events, topics, or other repetitive features (such as supporting an issue or taking part in actions), while eliminating recall errors. Furthermore, relying on SMD can help researchers pre-test their hypotheses for future surveys by uncovering relevant underlying discursive patterns or by making smaller-scale qualitative observations.

\section{Summary and concluding remarks}

The aim of this article was to provide a review of published papers on the complementarity of SMD and survey data for PO research. We started this review by situating our work within theoretical advances concerning the complementarity of both data source. There has been extensive work underlying the opportunities and (quality) challenges of SMD for answering social research questions. However, research attention has only recently turned to SMD as a source of expression of PO and of its measurement. Consequently, there is a need for more research to uncover the ways in which SMD can be best used for fostering the understanding of PO.

The main contribution of our review is to provide a complete picture of the empirical research on the topic while calling attention to the pros and cons of each approach and possible future paths of advancements. Though this review might not be exhaustive, it has enabled us to show six major complementarity approaches which were identified as responding to four different research purposes. Below we highlight the main research paths for each approach. Using both data sources complementarily for prediction purposes was by far the most prominent approach and it remains a research area which raises many questions about the potential generalisability of the findings, namely in terms of the representativeness and validity of social media measurements of PO. We believe that the most important difficulty lies perhaps in the manner in which these studies deduce political opinions or attitudes from SMD. Survey researchers readily admit that opinions are more difficult to measure than behaviour because they involve what people think and not just how they act. Thereby, the 
choice to rely on sentiment analysis or merely on volume metrics (such as the number of retweets or mentions) seems unclear, at least for the near future.

Approaches concerned with improving sustainability have a significant potential for advancing social research, as they allow researchers to combine the richness of SMD content with established survey measures. When SMD are used in similar contexts to survey data, we believe that a critical view should prevail, informed by current social science best practices and expertise. For instance, whereas surveys draw a sample of carefully worded and standardised questions, social media can cover many topics as well as different facets of the same topic, which are not necessarily defined a priori on a theoretical basis. This research avenue is most likely to be fruitful for studies aiming to augment surveys by mapping discussions that are topical on social media, while allowing variations at country or regional levels of analysis to be discerned (e.g. Bennett et al. [10] on climate change opinions). Studies aiming to compare both data sources are certainly the most suitable to help improve our understanding about when and how both data sources can be validly combined. Survey methodologists can play a decisive role, notably by paying attention to the type of (open-ended) questions that can be more directly comparable with SMD. This direction can also inform the lack of consistent evidence for the first prediction approach.

Alternatively, studies aiming to improve reliability see research as mostly requiring control for the still severe limitations of using SMD appropriately in a PO context. In this respect, studies enriching survey data with SMD offer a solution to the fact that social media often lack relevant individual information, such as respondent's attributes (e.g. sociodemographic characteristics or personality traits) or key outcome variables (e.g. voting, social, or political attitudes). Additionally, the "survey as proxy" approach enables researchers to calibrate SMD according to standardized survey measures at the actor (e.g. political candidates or parties) or context levels by reversing the data linking strategy. Future paths for both approaches implicate opening up the analysis to non-individual levels.

Studies aiming to improve the interpretability of survey research by generating new insights or by recruiting respondents on social media for a second survey phase, and that use both data sources complementarily, offer additional fertile ways to consider for new analyses that would not be possible using survey data alone. In this view, SMD do not aim to replace opinion surveys, but aim to provide a broader context for interpreting opinion, which will then serve to improve the quality of survey questions. This research avenue is most likely to be useful for knowing more about hard-to-reach populations (e.g. the LGBTQI* or disabled persons communities) or topics that are difficult to survey (e.g. violence and racism), especially when conducting iterative phases of analysis. It is also useful to get "opinion climates" about topics which have long been under survey scrutiny (e.g. emerging concerns related to feminism or social inclusion) in order to develop "updated" survey measurements.

Bringing together the opportunities offered by these different approaches shows that samples of social media users do not necessarily have to be representative of the general public to be used meaningfully as a complement to surveys. Most importantly, we believe that SMD should supplement, but not replace, traditional methods and data sources in the study of PO. By keeping up with current developments, we believe that remaining in the framework of survey research when using both data sources complementarily is paramount for identifying potential non-survey data sources, accessing them, and assessing their quality and usefulness for the study of PO. Like mixed-method approaches combining qualitative and quantitative data (e.g. [36]), the primary motive for complementing survey and SMD with one another is to allow researchers to mix datasets in a meaningful way for developing an overall interpretation. 


\subsection{Technical and ethical note}

Regarding sustainability, it is important to consider that the patterns of social media consumption are influenced not only by user preferences, but also by technological changes and the availability of the platforms. For instance, social media companies may not survive and whole platforms could disappear, thus impeding data access. With changes in consumption patterns, PO may be difficult to measure consistently over time. From a more technical perspective, it is also important to assess the extent to which databases composed of social media texts collected by different means (e.g. different search queries or different platform algorithms) might raise consistency and replicability issues (e.g. [34]). As for reliability, several issues are worth considering. Even though SMD can provide complementary information to survey estimates though linkage, there are sometimes concerns about the veracity or honesty of the information collected. For instance, SMD may increase the potential for social stigmatisation, causing users to be more reluctant to share their true opinions [63]. However, the opposite may also be true: users could express more radical opinions to gain social approval (e.g. disinhibition effect). The identity of those who post can also raise veracity concerns [55], and it may be difficult to distinguish sarcastic content from texts that are straight-forwardly positive or negative (e.g. [35]). Another important issue is that we usually know how many people have liked a post, clicked on a link, or retweeted a message, but we rarely know how many people have seen the item and chosen not to take any action [77]. Furthermore, due to algorithms that favour selective exposure and homophily of opinion [6, 17], it is important to assess the extent to which findings derived from online opinion generate more polarised opinions than the ones that would be obtained through the private setting of surveys.

When researchers aim to generate new insights, they should consider that each social media platform has particular arrangements. For instance, the orientation of the content (e.g. political, family-oriented, business-oriented) as well as the scope of the content (e.g. possible bias toward more visible events) can play a decisive role on what content is available and which user profiles are most likely to be active on the social media platform. Furthermore, the nature of the platform allows for different levels of engagement in debates (e.g. Twitter is mostly used for short text content, while YouTube and Instagram allow sharing and commenting on videos and pictures). Functional capabilities can not only influence the ways of recruiting respondents for a second survey phase (e.g. direct messages), but also the identifying of sub-groups of interest (e.g. differences between friend and follower networks, and the reciprocity of follower networks). In addition, social media platforms may give users control over the availability of the information (e.g. to suppress or filter unwanted comments), which will again impact what is available from whom and on what.

For each research purpose, we should also consider that there are important ethical factors that are likely to influence the possible paths of research relying on SMD. Each platform has its own rules which are subject to change at any time. For instance, anonymity settings also affect the content of SMD, with growing concerns about surveillance and the resulting loss of privacy $[29,76,78]$, thus influencing what people are willing to post. There are also evolving rules about the banning of particular words and behaviours, as well as users, which may influence research findings (especially when conducting longitudinal research). SMD are private property of tech companies and can be arbitrarily erased or made inaccessible, compromising the replicability of research.

\subsection{Outlook}

Our review has several limitations. First, it focuses on social media but do not include other data sources that are frequently compared to survey data to model PO (e.g. Google trends, 
mainstream media, or administrative data). We thus encourage future research to extend the proposed complementary framework to additional data sources. This would allow the building of knowledge about the most suitable ways of combining these data for answering specific research purposes. Furthermore, our review entails a conceptual aim with less focus on the variety of methods used to either collect, clean, analyse, and aggregate the data to generate statistics. Discussing the pros and cons of methodologies employed by these papers could constitute the object of another review.

Notwithstanding these limitations, our study is not only of interest for social and political scientists concerned by the declining response rates and restrictive budgeting for survey research [57]. As social media have been established as multifunctional tools, and many companies and researchers implement strategies based on social media to collect opinions, make predictions, study behaviours, conduct experiments, or recruit hard-to-reach populations, this review is also of interest for practitioners.

Extracting PO from social media text can foster social sciences by moving it forward as an applied field, thus bridging gaps between computational models and interpretative research. We see this collaboration as particularly important for developing more advanced and reliable measures of opinion from social media texts. This also constitutes an opportunity to challenge the opposition of the so-called data-driven and theory-driven approaches, a simplistic dichotomy which further consolidates the misconception that social research can be conducted by relying solely on text-based data. We encourage researchers to acknowledge the different conceptualisation of opinion when measured by SMD and surveys, and we advise them to adopt a mixed-method strategy where the complementarity of both data is paramount.

\section{Appendix}

Table 2 List of theoretical papers focusing on the combination of survey and social media data $(n=46$, continues next pages)

\begin{tabular}{|c|c|c|c|c|}
\hline Author(s) & Date & Title & Source & Focus \\
\hline Blumenthal & 2005 & $\begin{array}{l}\text { Toward an open-source methodology: } \\
\text { What we can learn from the } \\
\text { blogosphere }\end{array}$ & The Public Opinion Quarterly & General \\
\hline Gayo-Avello & 2011 & $\begin{array}{l}\text { Don't turn social media into another } \\
\text { Literary Digest poll }\end{array}$ & Communications of the ACM & Prediction \\
\hline $\begin{array}{l}\text { Sobkowicz } \\
\text { et al. }\end{array}$ & 2012 & $\begin{array}{l}\text { Opinion mining in social media: } \\
\text { Modeling, simulating, and } \\
\text { forecasting political opinions in the } \\
\text { web }\end{array}$ & $\begin{array}{l}\text { Government Information } \\
\text { Quarterly }\end{array}$ & Prediction \\
\hline $\begin{array}{l}\text { Boyd \& } \\
\text { Crawford }\end{array}$ & 2012 & $\begin{array}{l}\text { Critical questions for big data: } \\
\text { Provocations for a cultural, } \\
\text { technological, and scholarly } \\
\text { phenomenon }\end{array}$ & $\begin{array}{l}\text { Information, } \\
\text { Communication \& } \\
\text { Society }\end{array}$ & General \\
\hline $\begin{array}{l}\text { Metaxas \& } \\
\quad \text { Mustafaraj }\end{array}$ & 2012 & Social media and the elections & Science & Prediction \\
\hline Gayo-Avello & 2012 & $\begin{array}{l}\text { I Wanted to Predict Elections with } \\
\text { Twitter and all I got was this Lousy } \\
\text { Paper }\end{array}$ & arXiv Preprint & Prediction \\
\hline Gayo-Avello & 2012 & $\begin{array}{l}\text { No, You Cannot Predict Elections with } \\
\text { Twitter }\end{array}$ & IEEE Internet Computing & Prediction \\
\hline
\end{tabular}


Table 2 (continued)

\begin{tabular}{|c|c|c|}
\hline Author(s) & Date & Title \\
\hline Smith & 2013 & $\begin{array}{l}\text { Survey-research paradigms old and } \\
\text { new }\end{array}$ \\
\hline Couper & 2013 & $\begin{array}{l}\text { Is the sky falling? New technology, } \\
\text { changing media, and the future of } \\
\text { surveys }\end{array}$ \\
\hline Baker et al. & 2013 & $\begin{array}{l}\text { Summary Report of the AAPOR Task } \\
\text { Force on Non-probability Sampling }\end{array}$ \\
\hline Schoen et al. & 2013 & $\begin{array}{l}\text { The Power of Prediction with Social } \\
\text { Media }\end{array}$ \\
\hline Gayo-Avello & 2013 & $\begin{array}{l}\text { A Meta-Analysis of State-of-the-Art } \\
\text { Electoral Prediction From Twitter } \\
\text { Data }\end{array}$ \\
\hline $\begin{array}{l}\text { Stieglitz \& } \\
\text { Dang-- } \\
\text { Xuan }\end{array}$ & 2013 & $\begin{array}{l}\text { Social media and political } \\
\text { communication: a social media } \\
\text { analytics framework }\end{array}$ \\
\hline $\begin{array}{l}\text { Gayo-Avello } \\
\text { et al. }\end{array}$ & 2013 & $\begin{array}{l}\text { Understanding the predictive power of } \\
\text { social media }\end{array}$ \\
\hline $\begin{array}{l}\text { Ruths \& } \\
\quad \text { Pfeffer }\end{array}$ & 2014 & $\begin{array}{l}\text { Social Media for Large Studies of } \\
\text { Behavior }\end{array}$ \\
\hline Tufekci & 2014 & $\begin{array}{l}\text { Big Questions for social media Big } \\
\text { Data: Representativeness, Validity, } \\
\text { and Other Methodological Pitfalls }\end{array}$ \\
\hline Murphy et al. & 2014 & $\begin{array}{l}\text { Social media, sociality, and survey } \\
\text { research }\end{array}$ \\
\hline Murphy et al. & 2014 & $\begin{array}{l}\text { Social media in public opinion } \\
\text { research: Executive summary of the } \\
\text { aapor task force on emerging } \\
\text { technologies in public opinion } \\
\text { research }\end{array}$ \\
\hline
\end{tabular}

Hill \& Dever 2014 The Future of Social Media, Sociality, and Survey Research

Tang et al. 2014 Mining social media with social theories: a survey

Zagheni \& 2015 Demographic Research with

Weber Non-representative Internet Data

Resnick et al. 2015 What social media data we are missing and how to get it

Source

Focus

International Journal of Public Ontology

Opinion Research

Survey Research Methods General

Journal of Survey Statistics and General

Methodology

Internet Research

Prediction

Social Science Computer

Review

Prediction

Social Network Analysis and General

Mining volume

Internet Research

Prediction

Science

Behaviour

arXiv Preprint

Error sources

Book chapter (1): Social Media, Ontology

Sociality, and Survey

Research

Public Opinion Quarterly

General

Book chapter (12): Social

General

Media, Sociality, and Survey

Research

ACM SIGKDD Explorations

Newsletter

International Journal of

Manpower

The American Academy of Political and Social Science

Ampofo et 2015 Text Mining and Social Media: When ak. Quantitative Meets Qualitative, and Software Meets Humans

Hargittai 2015 Is Bigger Always Better? Potential Biases of Big Data Derived from Social Network Sites

Schober et al. 2016 Social media analyses for social measurement

Olteanu et al. 2016 Social Data: Biases, Methodological Pitfalls, and Ethical Boundaries

Junngherr 2016 Twitter use in election campaigns: A systematic literature review

Spiro 2016 Research opportunities at the intersection of social media and survey data

RJ Dalton 2016

Book chapter (8): Innovations in Digital Research Methods

The American Academy of Political and Social Science

Public Opinion Quarterly General

Frontiers in Big Data Error sources

Journal of Information Prediction Technology \& Politics

Current Opinion in Psychology Linking

International Journal of Behaviour Sociology 
Table 2 (continued)

\begin{tabular}{|c|c|c|c|c|}
\hline Author(s) & Date & Title & Source & Focus \\
\hline & & $\begin{array}{l}\text { The potential of big data for the } \\
\text { cross-national study of political be- } \\
\text { havior }\end{array}$ & & \\
\hline $\begin{array}{l}\text { Johnson \& } \\
\text { Smith }\end{array}$ & 2017 & $\begin{array}{l}\text { Big Data and Survey Research: } \\
\text { Supplement or Substitute? }\end{array}$ & $\begin{array}{l}\text { Book chapter: Seeing Cities } \\
\text { Through Big Data }\end{array}$ & Linking \\
\hline $\begin{array}{l}\text { Hsieh \& } \\
\quad \text { Murphy }\end{array}$ & 2017 & Total Twitter error & $\begin{array}{l}\text { Book chapter (2): Total Survey } \\
\text { Error in Practice }\end{array}$ & Error sources \\
\hline Salleh & 2017 & $\begin{array}{l}\text { From survey to social media: Public } \\
\text { opinion and politics in the age of big } \\
\text { data }\end{array}$ & Science & General \\
\hline Pal & 2017 & $\begin{array}{l}\text { Studying political communication on } \\
\text { Twitter: the case for small data }\end{array}$ & $\begin{array}{l}\text { Current Opinion in Behavioral } \\
\text { Sciences }\end{array}$ & Small data \\
\hline $\begin{array}{l}\text { Salunkhe } \\
\text { et al. }\end{array}$ & 2017 & $\begin{array}{l}\text { A review: Prediction of election using } \\
\quad \text { twitter sentiment analysis }\end{array}$ & $\begin{array}{l}\text { International Journal of } \\
\text { Advanced Research in } \\
\text { Science, Communication and } \\
\text { Technology }\end{array}$ & Prediction \\
\hline Klašnja et al. & 2018 & $\begin{array}{l}\text { Measuring Public Opinion with social } \\
\quad \text { media Data }\end{array}$ & $\begin{array}{l}\text { Book chapter: The Oxford } \\
\text { Handbook of Polling and } \\
\text { Survey Methods }\end{array}$ & General \\
\hline Jungherr & 2018 & Normalizing digital trace data & $\begin{array}{l}\text { Book chapter: Digital } \\
\text { Discussions }\end{array}$ & General \\
\hline Kwak \& Cho & 2018 & $\begin{array}{l}\text { Analyzing public opinion with social } \\
\text { media data during election periods: } \\
\text { A selective literature review }\end{array}$ & $\begin{array}{l}\text { Asian Journal for Public } \\
\text { Opinion Research }\end{array}$ & Prediction \\
\hline Szreder & 2018 & Will big data affect opinion polls? & Archives of Data Science & General \\
\hline Freelon & 2019 & $\begin{array}{l}\text { Inferring individual-level characteris- } \\
\text { tics from digital trace data: Issues } \\
\text { and recommendations }\end{array}$ & $\begin{array}{l}\text { Book chapter: Digital } \\
\text { Discussions }\end{array}$ & Demographic \\
\hline Trottier & 2019 & $\begin{array}{l}\text { A research agenda for social media } \\
\text { surveillance }\end{array}$ & Fast Capitalism & General \\
\hline Sen et al. & 2019 & $\begin{array}{l}\text { A Total Error Framework for Digital } \\
\text { Traces of Humans }\end{array}$ & arXiv Preprint & Error sources \\
\hline $\begin{array}{l}\text { Salvatore } \\
\quad \text { et al. }\end{array}$ & 2020 & $\begin{array}{l}\text { Social Media and Twitter Data Quality } \\
\quad \text { for New Social Indicators }\end{array}$ & Social Indicators Research & Error sources \\
\hline Stier et al. & 2020 & $\begin{array}{l}\text { Integrating survey data and digital } \\
\text { trace data: key issues in developing } \\
\text { an emerging field }\end{array}$ & $\begin{array}{l}\text { Social Science } \\
\text { Computer Review }\end{array}$ & Linking \\
\hline Romele et al. & 2020 & $\begin{array}{l}\text { Digital hermeneutics: from interpreting } \\
\text { with machines to interpretational } \\
\text { machines }\end{array}$ & AI \& SOCIETY & Ontology \\
\hline Skoric et al. & 2020 & $\begin{array}{l}\text { Electoral and Public Opinion Forecasts } \\
\text { with social media Data: A } \\
\text { Meta-Analysis }\end{array}$ & Information & Prediction \\
\hline $\begin{array}{l}\text { Rousidis } \\
\text { et al. }\end{array}$ & 2020 & $\begin{array}{l}\text { Social media prediction: a literature } \\
\text { review }\end{array}$ & $\begin{array}{l}\text { Multimedia Tools and } \\
\text { Applications }\end{array}$ & Prediction \\
\hline $\begin{array}{l}\text { Chauhan } \\
\text { et al. }\end{array}$ & 2020 & $\begin{array}{l}\text { The emergence of social media data } \\
\text { and sentiment analysis in election } \\
\text { prediction }\end{array}$ & $\begin{array}{l}\text { Journal of Ambient } \\
\text { Intelligence and Humanized } \\
\text { Computing }\end{array}$ & Prediction \\
\hline
\end{tabular}




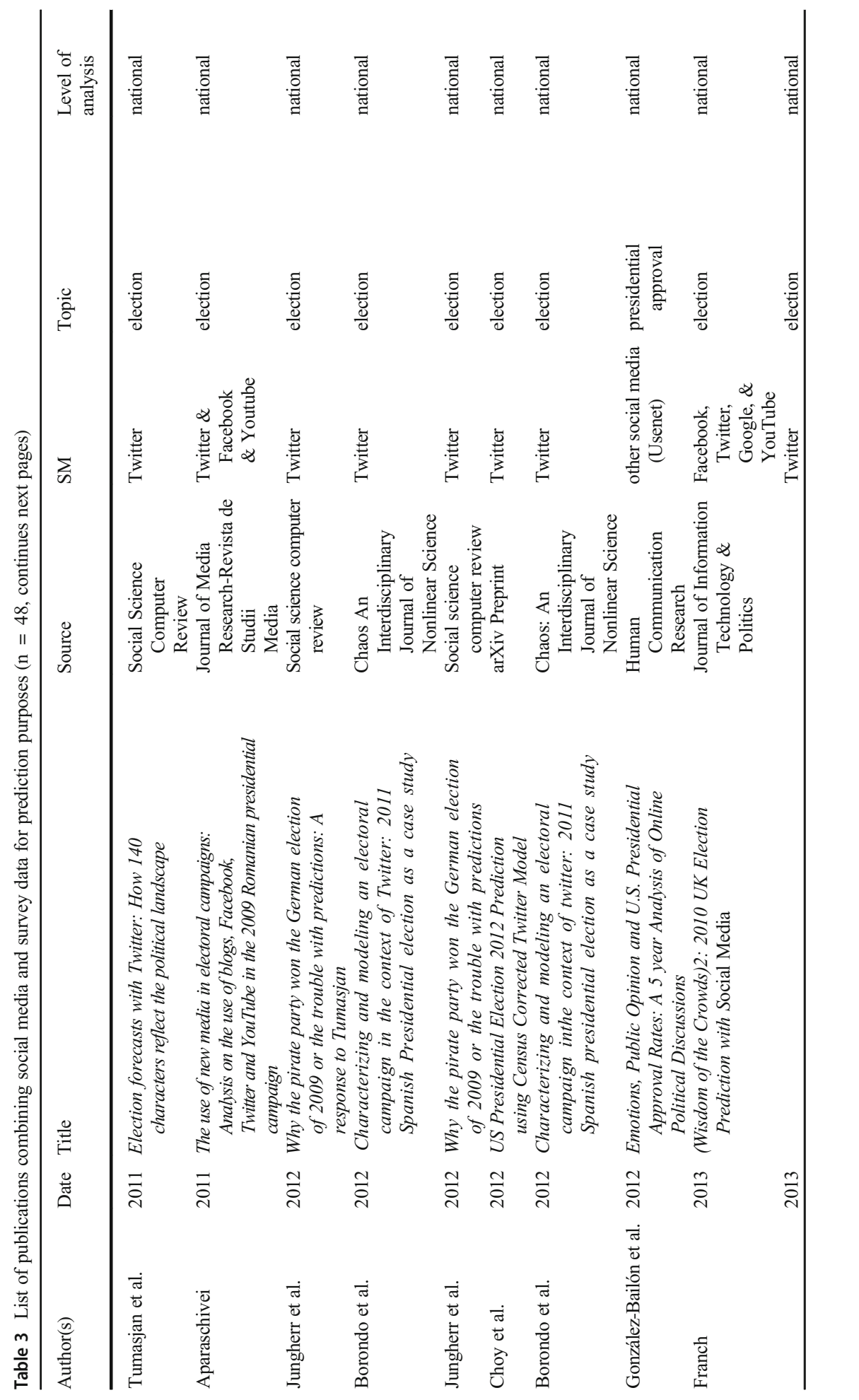




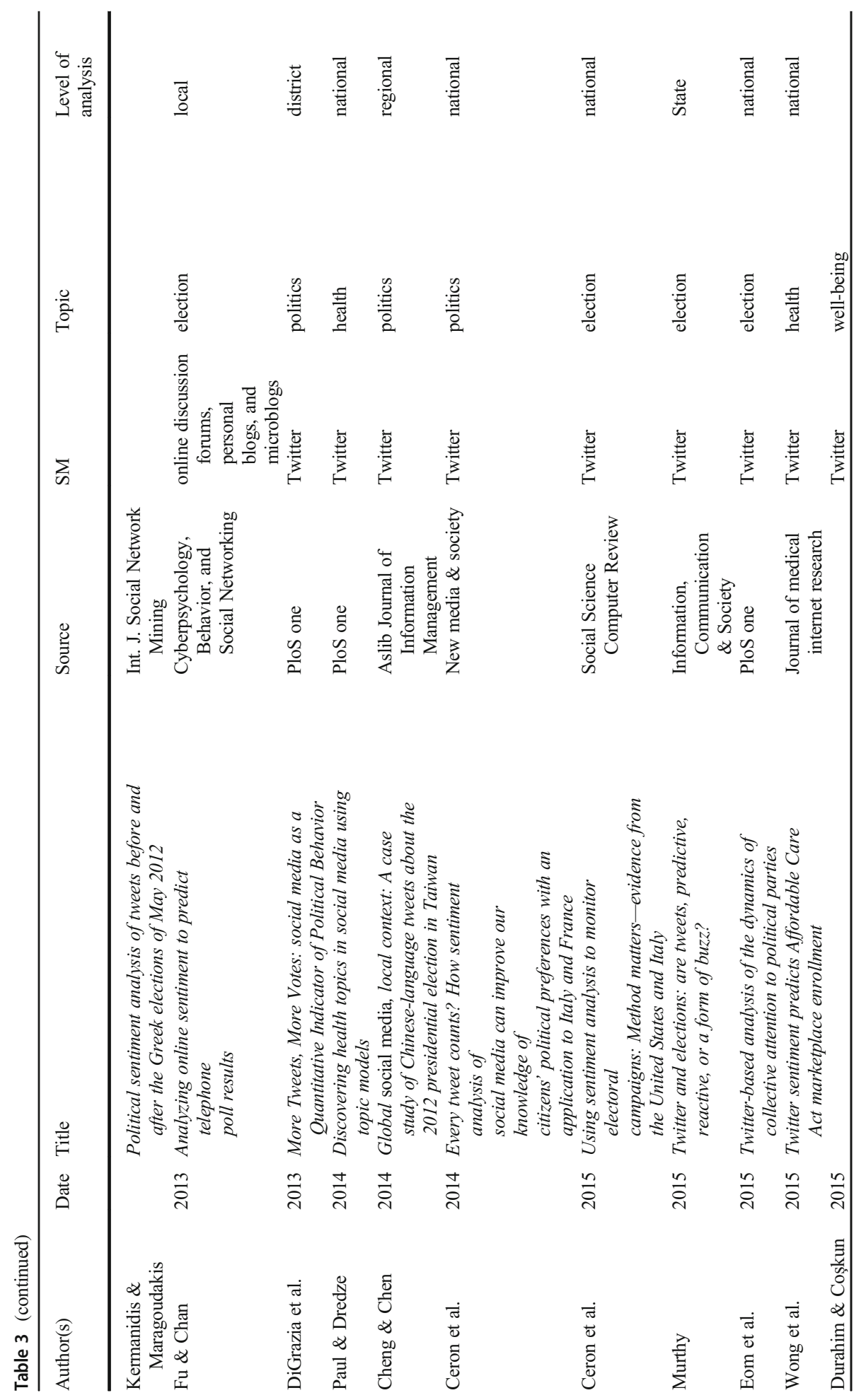




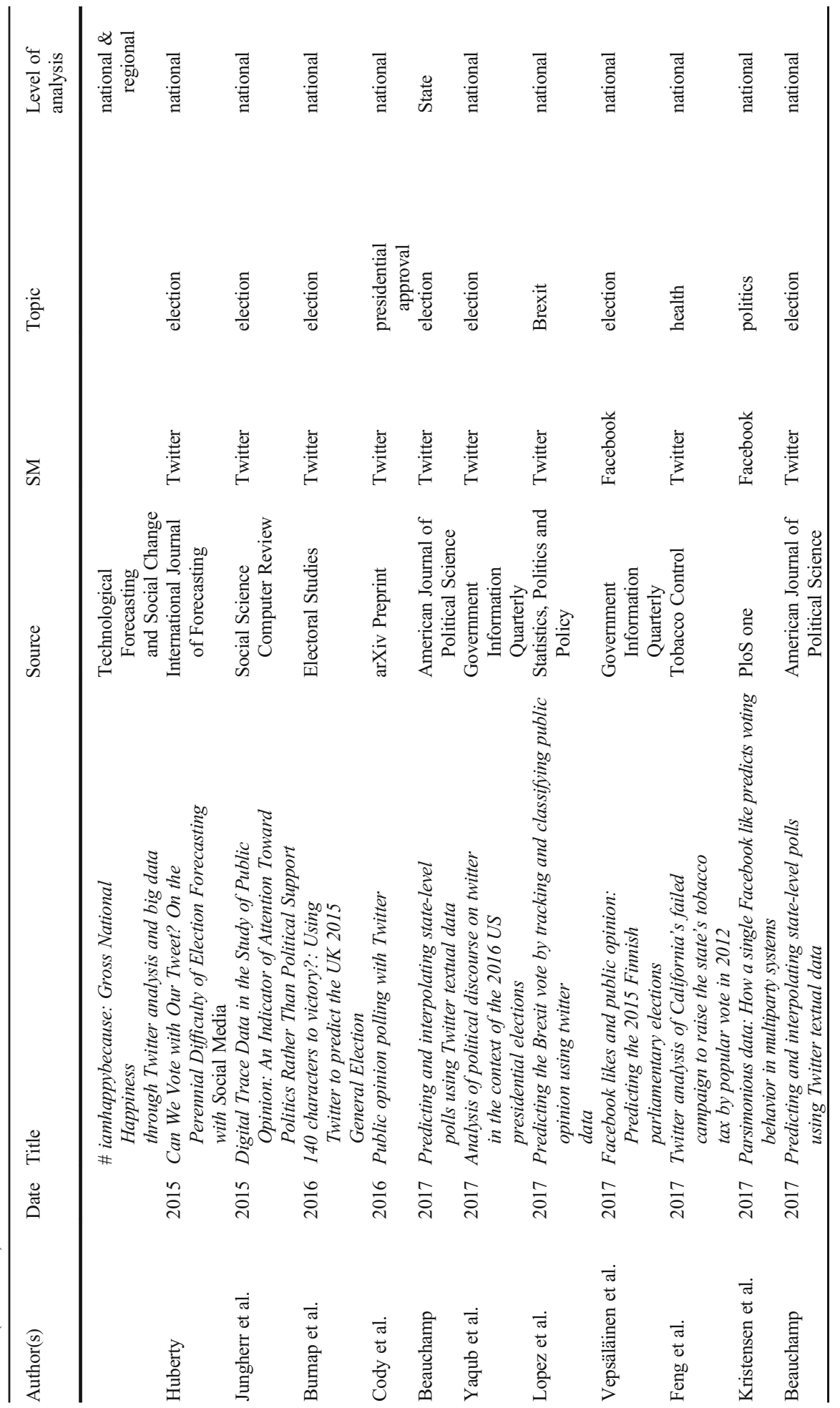




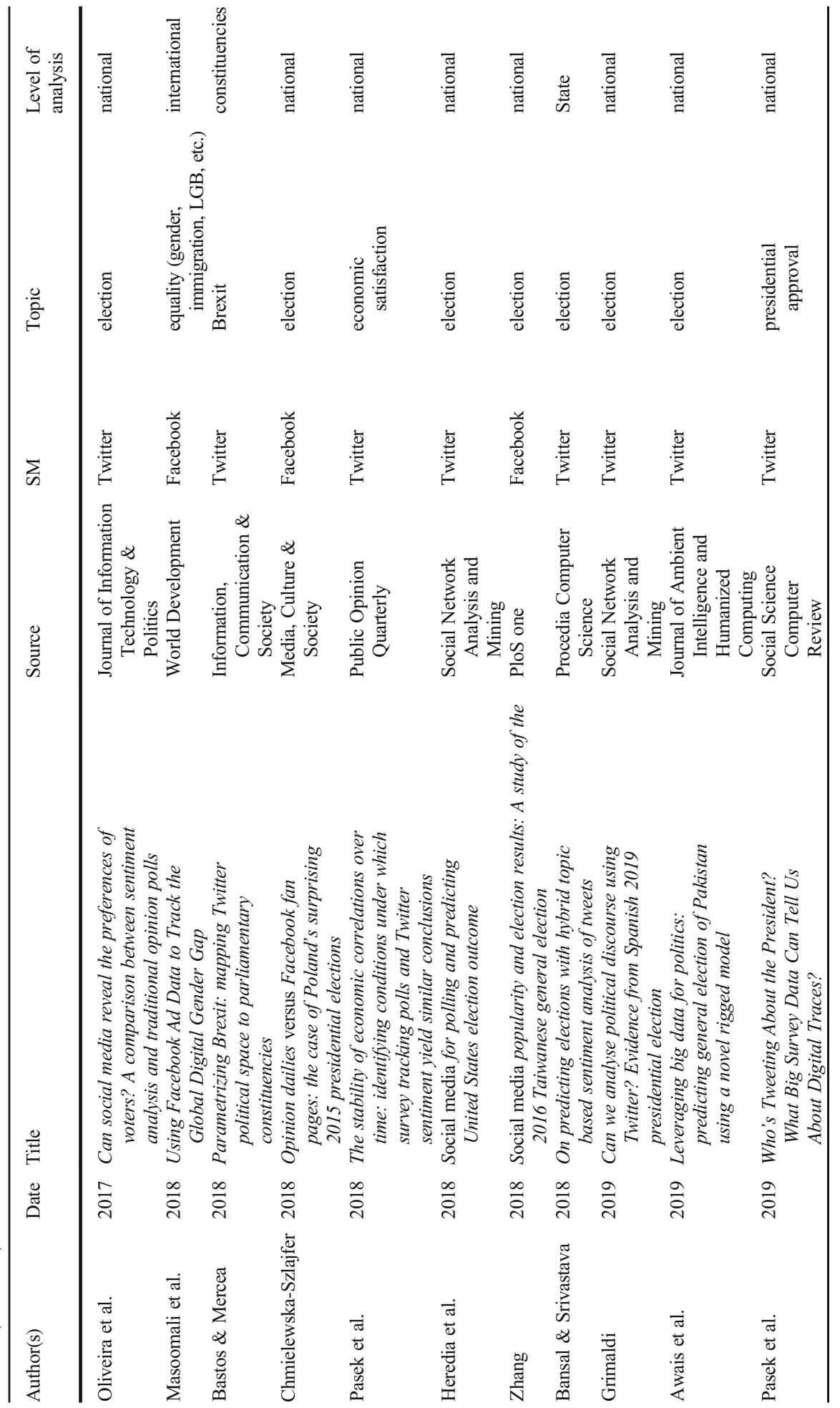




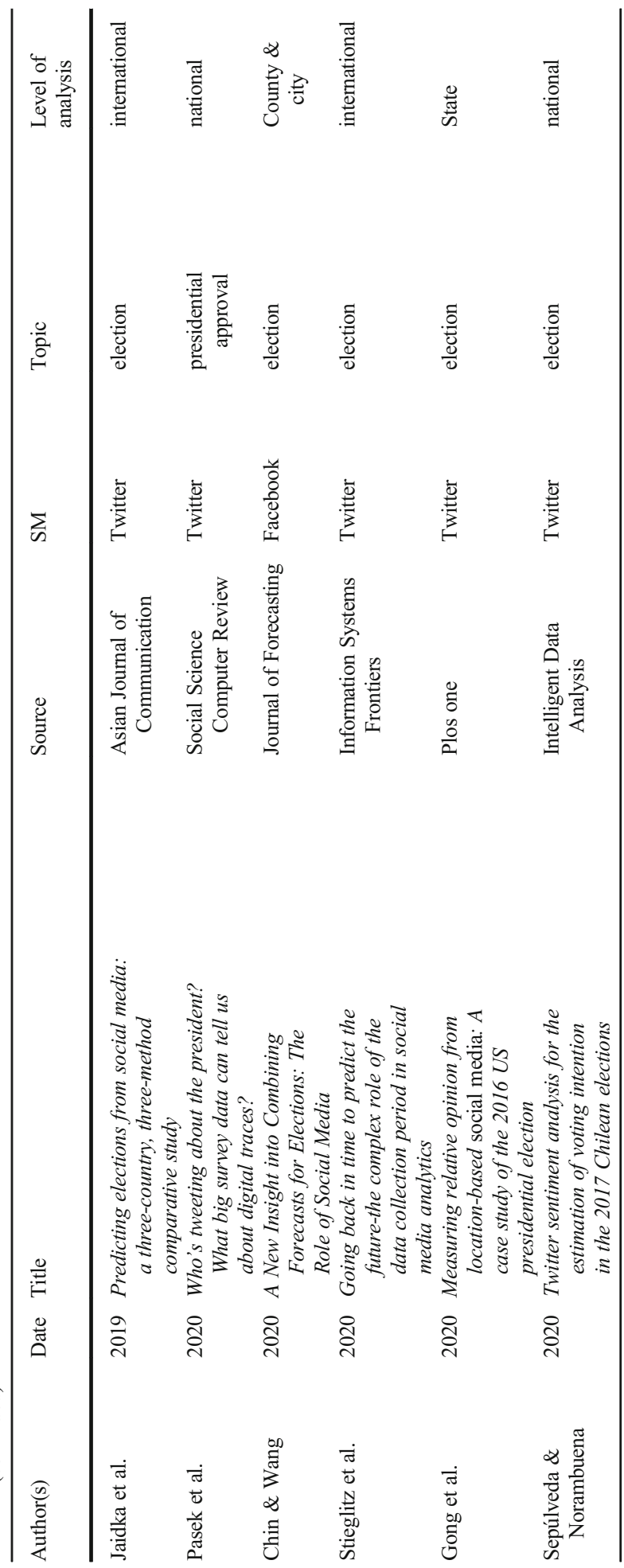




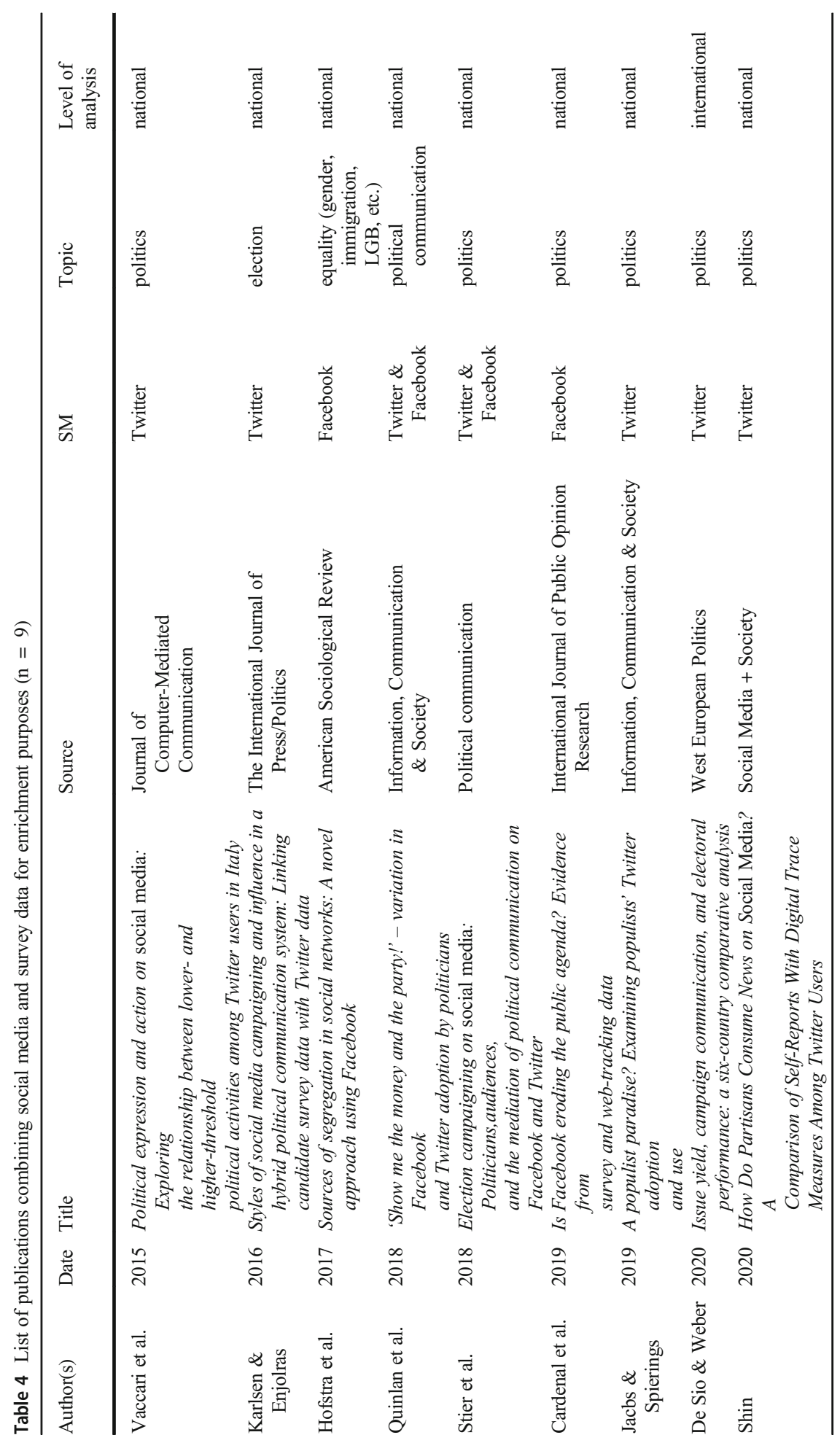




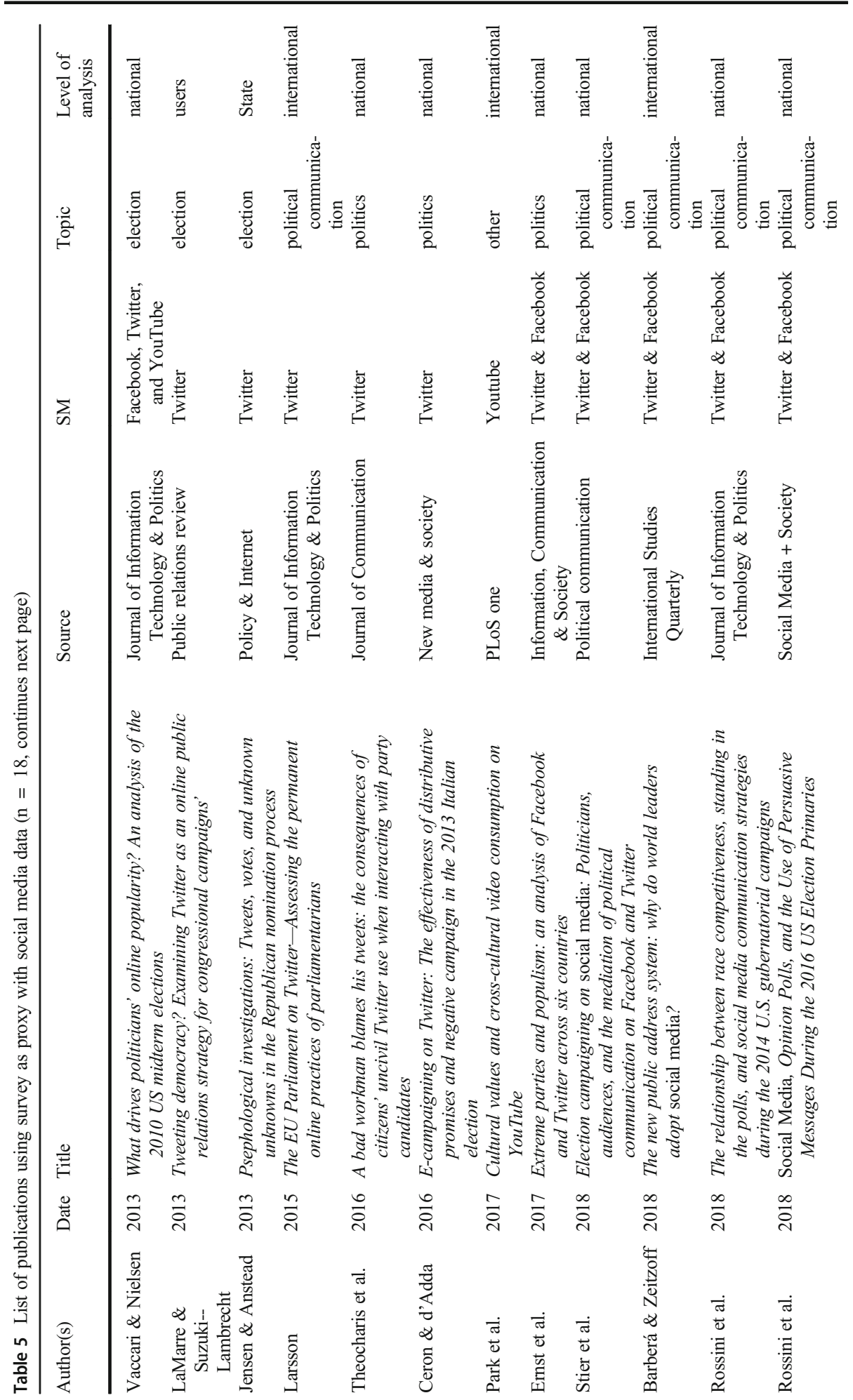




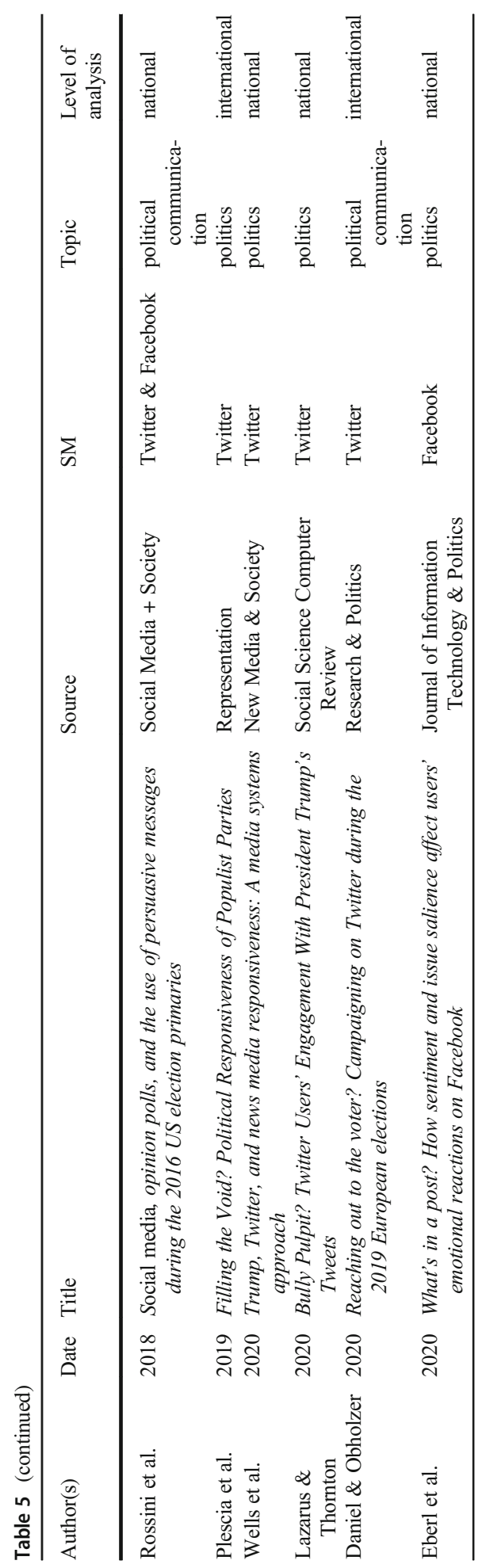









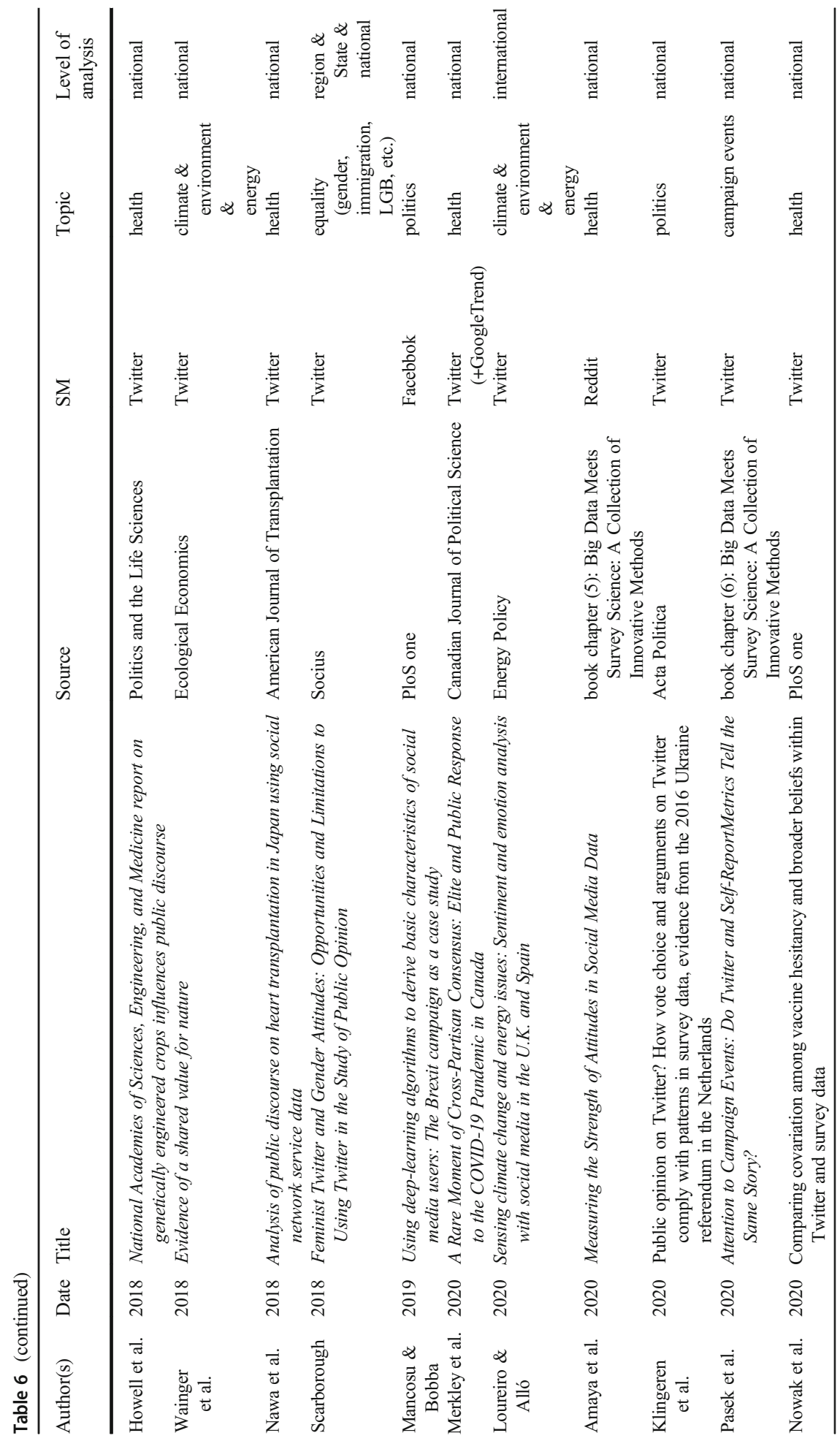




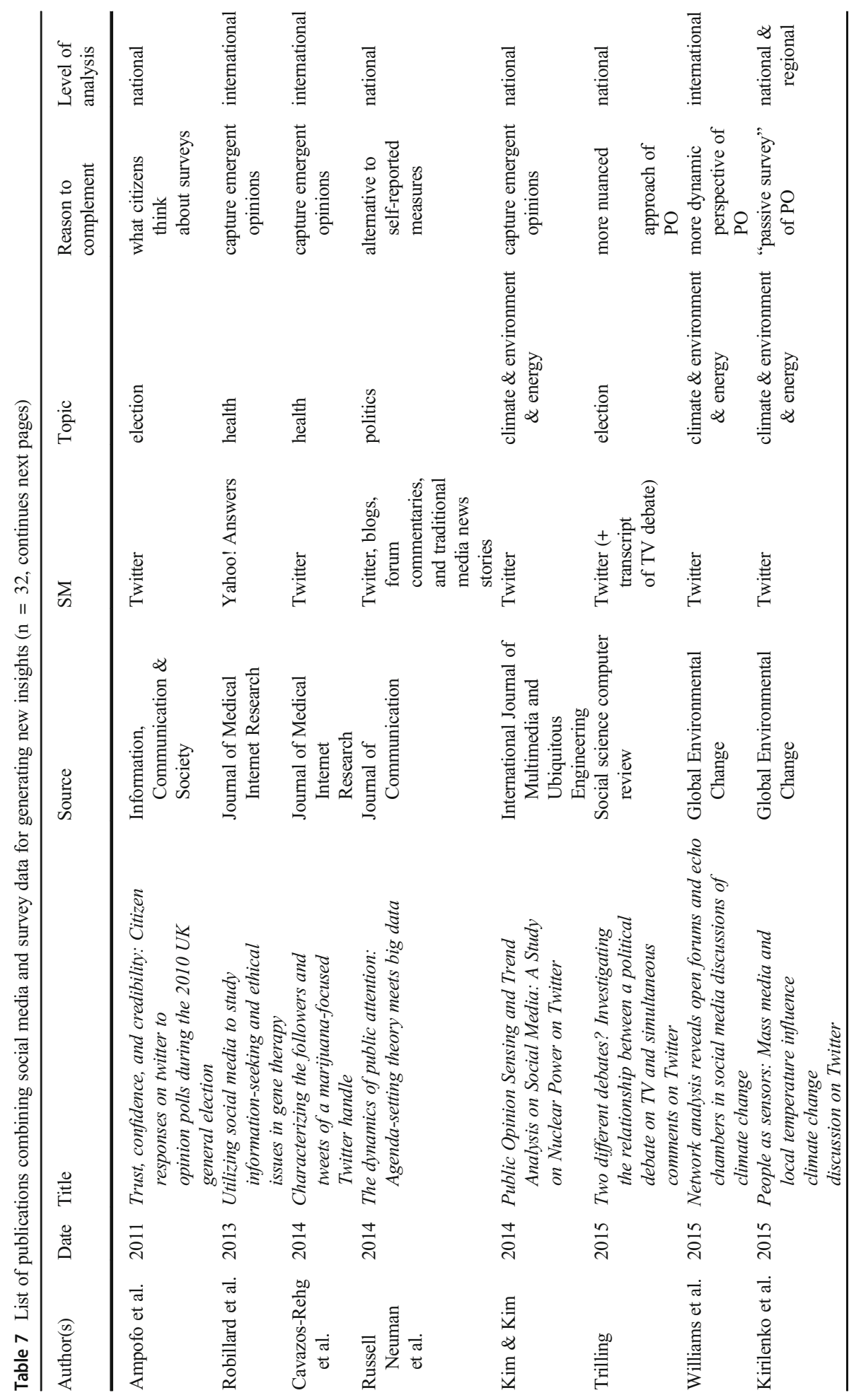




\begin{tabular}{|c|c|c|c|c|c|c|c|c|c|c|}
\hline 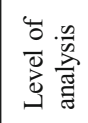 & 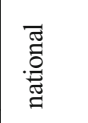 & 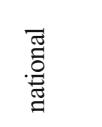 & 䔍 & 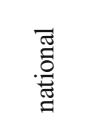 & 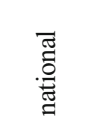 & 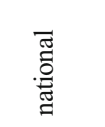 & 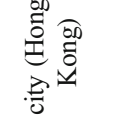 & 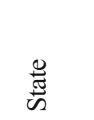 & 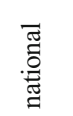 & 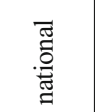 \\
\hline 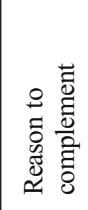 & 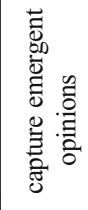 & 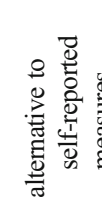 & 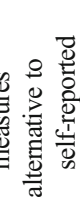 & 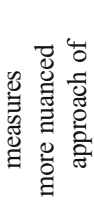 & 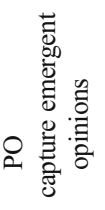 & & 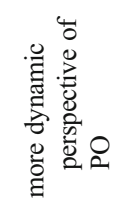 & 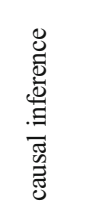 & 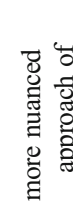 & \\
\hline 产 & 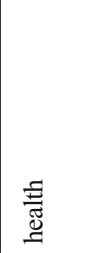 & 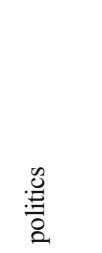 & 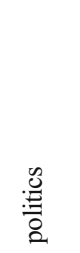 & 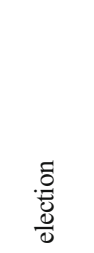 & 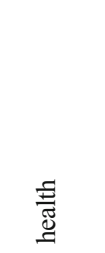 & 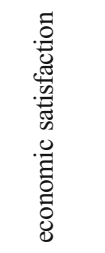 & 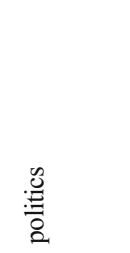 & 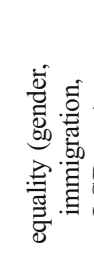 & 浸 & 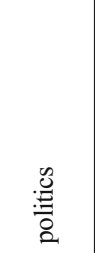 \\
\hline$\sum_{n}$ & 总 & 竧 & 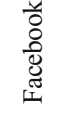 & 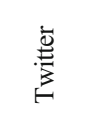 & 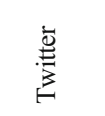 & 总 & 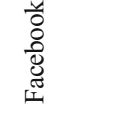 & 总 & 莺 & 产 \\
\hline $\begin{array}{l}\text { D } \\
\text { 言 } \\
\text { W }\end{array}$ & 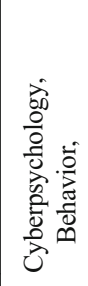 & 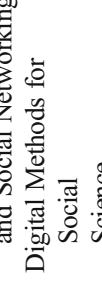 & 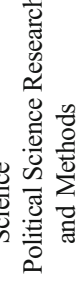 & 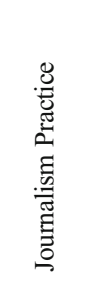 & 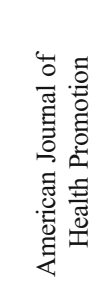 & 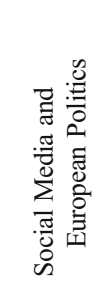 & 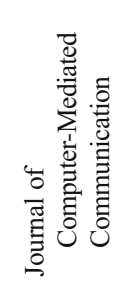 & 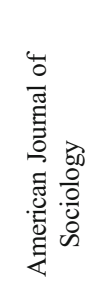 & 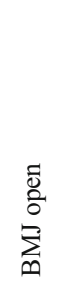 & 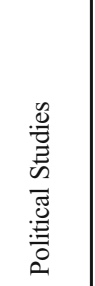 \\
\hline$\stackrel{\oplus}{\Xi}$ & 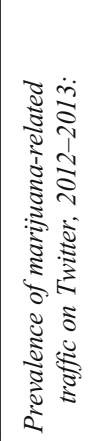 & 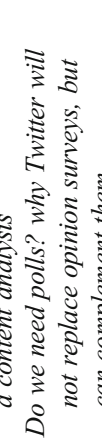 & 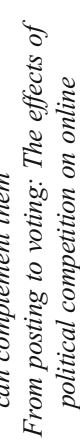 & 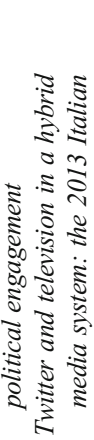 & 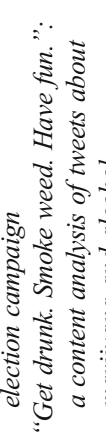 & 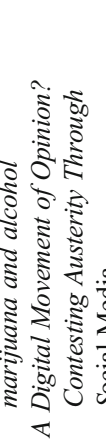 & 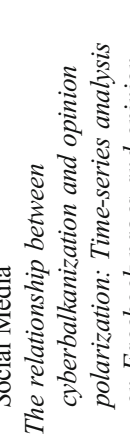 & 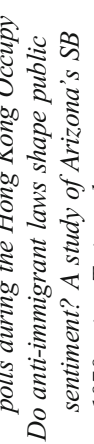 & 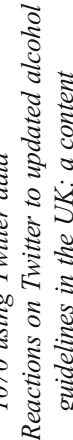 & 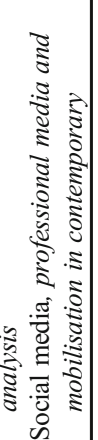 \\
\hline$\frac{\mathscr{0}}{\Delta 0}$ & $\stackrel{\sim}{\tilde{d}}$ & $\stackrel{\circ}{\stackrel{\sim}{\sim}}$ & $\stackrel{\circ}{\circ}$ & $\stackrel{\circ}{\circ}$ & $\hat{\bar{~}}$ & $\overline{\stackrel{\sim}{~}}$ & $\stackrel{\vec{\sim}}{\vec{\sim}}$ & $\overline{\bar{̀}}$ & 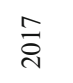 & $\overrightarrow{\bar{\sim}}$ \\
\hline 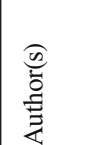 & 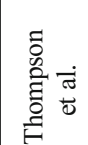 & 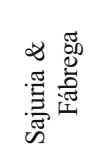 & 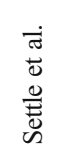 & 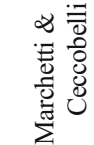 & 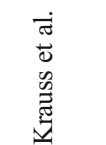 & 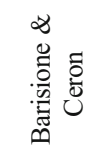 & 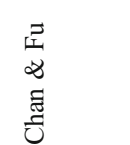 & $\frac{\mathscr{E}}{\frac{0}{L}}$ & 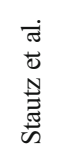 & 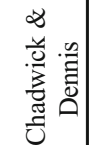 \\
\hline
\end{tabular}




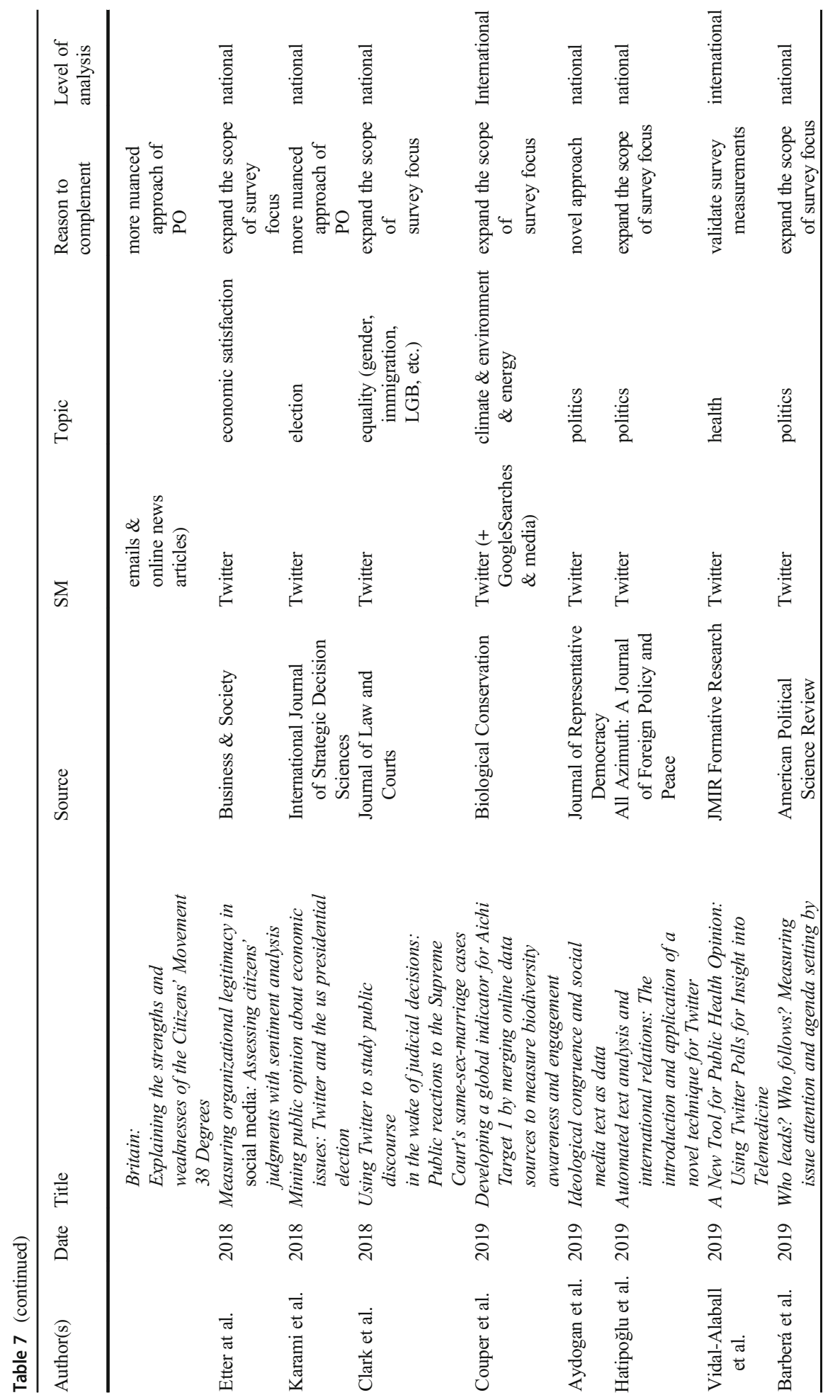




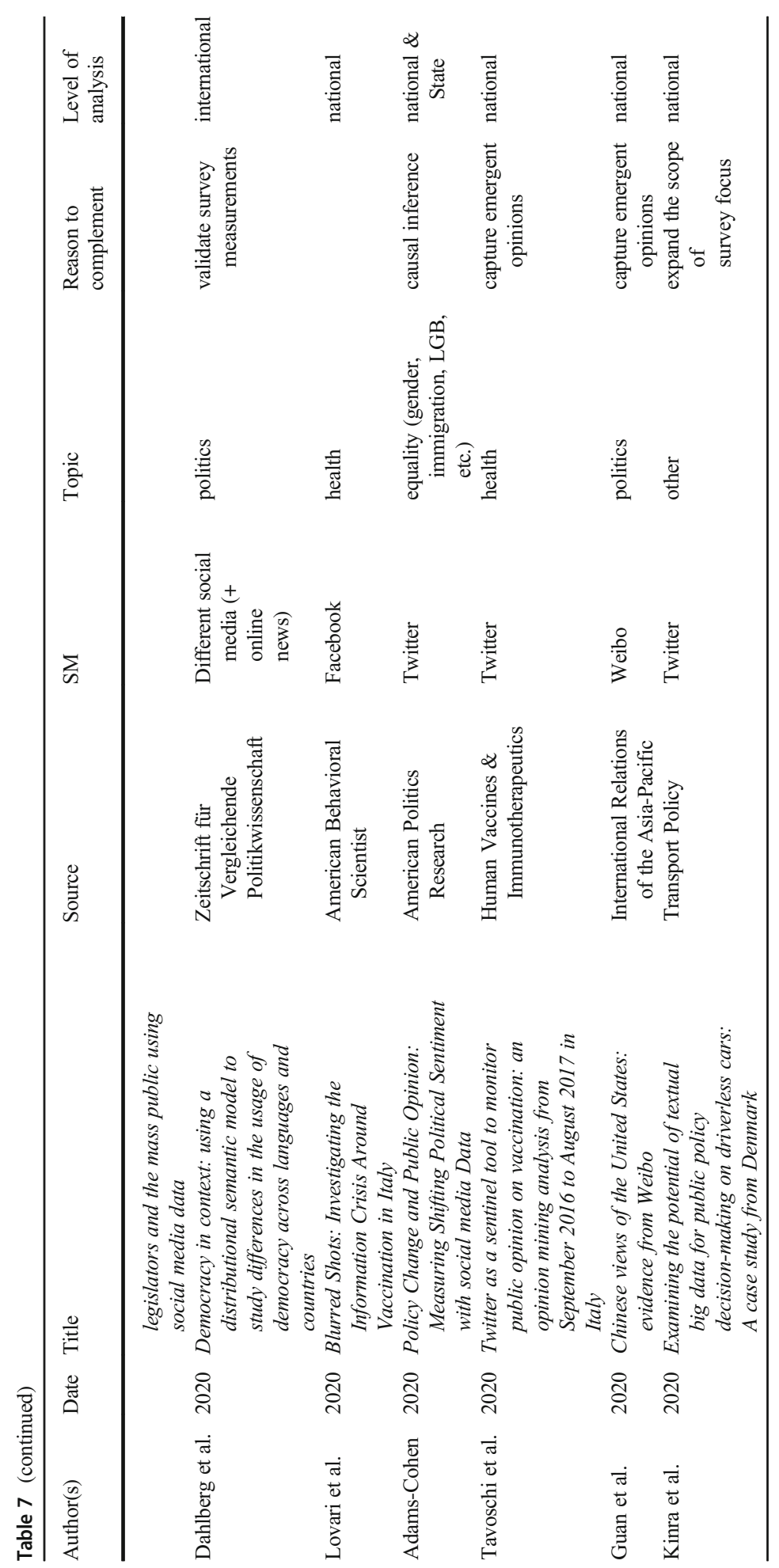




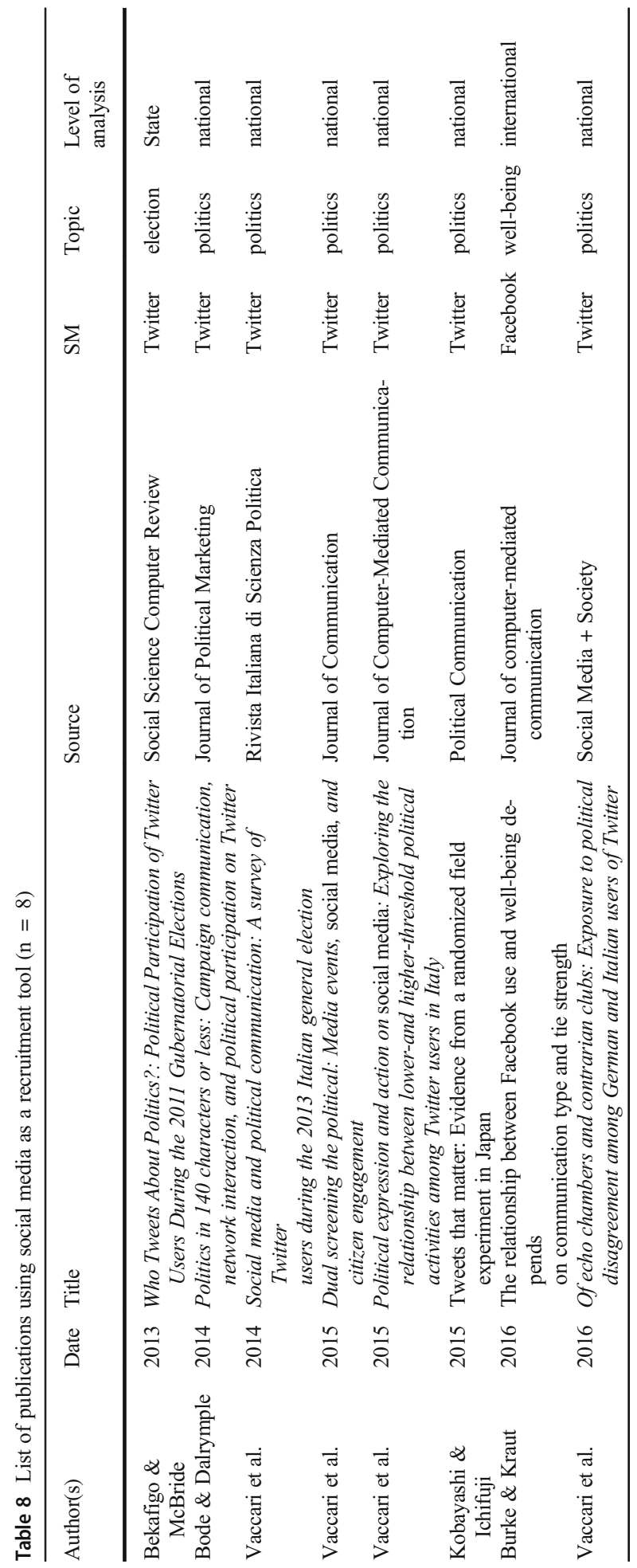


Code availability Not applicable;

Authors contribution All authors contributed to the design of the study. Maud Reveilhac planned the study, conducted the data analysis, and wrote the manuscript. All authors contributed to the review of the manuscript and approved the final version.

Funding Open access funding provided by University of Lausanne.

Data availability Please refer to the appendix.

\section{Declarations}

Conflict of interest We have no conflict of interests to disclose;

Open Access This article is licensed under a Creative Commons Attribution 4.0 International License, which permits use, sharing, adaptation, distribution and reproduction in any medium or format, as long as you give appropriate credit to the original author(s) and the source, provide a link to the Creative Commons licence, and indicate if changes were made. The images or other third party material in this article are included in the article's Creative Commons licence, unless indicated otherwise in a credit line to the material. If material is not included in the article's Creative Commons licence and your intended use is not permitted by statutory regulation or exceeds the permitted use, you will need to obtain permission directly from the copyright holder. To view a copy of this licence, visit http://creativecommons.org/licenses/by/4.0/.

\section{References}

1. Adams-Cohen NJ (2020) Policy change and public opinion: measuring shifting political sentiment with social media data. Am Politics Res 48(5):612-621. https://doi.org/10.1177/1532673X20920263

2. Amaya A, Bach R, Kreuter F, Keusch F (2020) Measuring the strength of attitudes in social media data. In: Hill C, Biemer P, Buskirk T, Japec L, Kirchner A, Kolenikov S, Lyberg L (eds) Big data meets survey science. Wiley, Hoboken, pp 163-192. https://doi.org/10.1002/9781118976357.ch5

3. Anstead N, O'Loughlin B (2015) Social media analysis and public opinion: the 2010 UK general election. J Comput-Mediat Commun 20(2):204-220. https://doi.org/10.1111/jcc4.12102

4. Bakker R, Hooghe L, Jolly S, Marks G, Polk J, Rovny J, Steenbergen M, Vachudova M (2021) Chapel Hill expert survey (CHES) Europe 1999-2019 trend file. EUI research data, Robert Schuman Centre for Advanced Studies, European University Institute. https://cadmus.eui.eu//handle/1814/69975. Accessed 1 June 2020

5. Bakshy E, Messing S, Adamic LA (2015) Exposure to ideologically diverse news and opinion on Facebook. Science 348(6239):1130-1132. https://doi.org/10.1126/science.aaa1160

6. Barberá P, Jost JT, Nagler J, Tucker JA, Bonneau R (2015) Tweeting from left to right: is online political communication more than an echo chamber? Psychol Sci 26(10):1531-1542. https://doi.org/10.1177/ 0956797615594620

7. Barberá P, Casas A, Nagler J, Egan PJ, Bonneau R, Jost JT, Tucker JA (2019) Who leads? Who follows? Measuring issue attention and agenda setting by legislators and the mass public using social media data. Am Polit Sci Rev 113(4):883-901. https://doi.org/10.1017/S0003055419000352

8. Batrinca B, Treleaven PC (2015) Social media analytics: a survey of techniques, tools and platforms. AI \& Soc 30(1):89-116. https://doi.org/10.1007/s00146-014-0549-4

9. Bekafigo MA, McBride A (2013) Who tweets about politics?: political participation of twitter users during the 2011Gubernatorial elections. Soc Sci Comput Rev 31(5):625-643. https://doi.org/10.1177/ 0894439313490405

10. Bennett J, Rachunok B, Flage R, Nateghi R (2021) Mapping climate discourse to climate opinion: an approach for augmenting surveys with social media to enhance understandings of climate opinion in the United States. PLoS One 16(1):e0245319. https://doi.org/10.1371/journal.pone.0245319 
11. Biemer PP, Christ SL (2008) Weighting survey data. In: de Leeuw ED, Hox J, Dillman D (eds) International handbook of survey methodology. New York, Taylor and Francis Group, pp 317-341

12. Bode L, Dalrymple KE (2016) Politics in 140 characters or less: campaign communication, network interaction, and political participation on twitter. J Political Mark 15(4):311-332. https://doi.org/10.1080/ 15377857.2014.959686

13. Brick JM, Williams D (2013) Explaining rising nonresponse rates in cross-sectional surveys. Ann Am Acad Political Soc Sci 645(1):36-59

14. Cardenal AS, Galais C, Majó-Vázquez S (2019) Is Facebook eroding the public agenda? Evidence from survey and web-tracking data. Int J Public Opin Res 31(4):589-608. https://doi.org/10.1093/ijpor/edy025

15. Chauhan P, Sharma N, Sikka G (2020) The emergence of social media data and sentiment analysis in election prediction. J Ambient Intell Humaniz Comput 12(2):2601-2627. https://doi.org/10.1007/s12652020-02423-y

16. Clark TS, Staton JK, Wang Y, Agichtein E (2018) Using twitter to study public discourse in the wake of judicial decisions: public reactions to the supreme Court's same-sex-marriage cases. J Law Courts 6(1):93126. https://doi.org/10.1086/695423

17. Conover MD, Ratkiewicz J, Francisco M, Gonçalves B, Menczer F, Flammini A (2011) Political polarization on twitter. Proceedings of the $5^{\text {th }}$ International AAAI Conference on Weblogs and Social Media, 5(1), 89-96. https://ojs.aaai.org/index.php/ICWSM/article/view/14126

18. Couper MP (2013) Is the sky falling? New technology, changing media, and the future of surveys. Surv Res Methods 7(3):145-156. https://doi.org/10.18148/srm/2013.v7i3.5751

19. Daas P, Roos M, van de Ven M, Neroni J (2012) Twitter as a potential source for official statistics in the Netherlands. Discussion paper (201221). Centraal Bureau voor de Statistiek, Den Haag. http://pietdaas.nl/ beta/pubs/pubs/DiscPaper_Twitter.pdf. Accessed 1 June 2020

20. Dahlberg S, Axelsson S, Holmberg S (2020) Democracy in context: using a distributional semantic model to study differences in the usage of democracy across languages and countries. Zeitschrift Für Vergleichende Politikwissenschaft 14(4):425-459. https://doi.org/10.1007/s12286-020-00472-3

21. Davis MA, Zheng K, Liu Y, Levy H (2017) Public response to Obamacare on twitter. J Med Internet Res 19(5):e6946. https://doi.org/10.2196/jmir.6946

22. De Heer W, De Leeuw E (2002) Trends in household survey nonresponse: a longitudinal and international comparison. In: Groves RM, Dillman D, Eltinge JL, Little RJA (eds) Survey nonresponse. Wiley, New York, pp 41-54

23. De Sio LD, Weber T (2020) Issue yield, campaign communication, and electoral performance: a six-country comparative analysis. West Eur Polit 43(3):720-745. https://doi.org/10.1080/01402382.2019.1655968

24. Del Vicario M, Bessi A, Zollo F, Petroni F, Scala A, Caldarelli G, Stanley HE, Quattrociocchi W (2016) The spreading of misinformation online. Proc Natl Acad Sci 113(3):554-559. https://doi.org/10.1073/pnas. 1517441113

25. Diaz F, Gamon M, Hofman JM, Kiciman E, Rothschild D (2016) Online and social media data as an imperfect continuous panel survey. PLoS One 11(1):e0145406. https://doi.org/10.1371/journal.pone. 0145406

26. Digital Global Report (2020) Digital use around the world in July 2020. https://wearesocial.com/blog/2020/ 07/digital-use-around-the-world-in-july-2020. Accessed 16 August 2020

27. Dubois E, Gruzd A, Jacobson J (2018) Journalists' use of social media to infer public opinion: the citizens' perspective. Soc Sci Comput Rev 38(1):57-74. https://doi.org/10.1177/0894439318791527

28. Eberl J-M, Tolochko P, Jost P, Heidenreich T, Boomgaarden HG (2020) What's in a post? How sentiment and issue salience affect users' emotional reactions on Facebook. J Inform Technol Polit 17(1):48-65. https://doi.org/10.1080/19331681.2019.1710318

29. Ellison NB, Vitak J, Steinfield C, Gray R, Lampe C (2011) Negotiating privacy concerns and social capital needs in a social media environment. In: Trepte S, Reinecke L (eds) Privacy online. Springer, London, pp 19-32

30. Ernst N, Engesser S, Büchel F, Blassnig S, Esser F (2017) Extreme parties and populism: an analysis of Facebook and twitter across six countries. Inf Commun Soc 20(9):1347-1364. https://doi.org/10.1080/ 1369118X.2017.1329333

31. Gayo-Avello D (2011) Don't turn social media into another 'literary digest' poll. Commun ACM 54(10): 121-128. https://doi.org/10.1145/2001269.2001297

32. Gayo-Avello D (2013) A Meta-analysis of state-of-the-art electoral prediction from twitter data. Soc Sci Comput Rev 31(6):649-679. https://doi.org/10.1177/0894439313493979

33. Gayo-Avello D, Metaxas P, Mustafaraj E (2011) Limits of electoral predictions using twitter. Proceedings of the 5th International AAAI Conference on Web and Social Media, 5(1), 490-493. https:/ojs.aaai.org/ index.php/ICWSM/article/view/14189

34. González-Bailón S, Wang N, Rivero A, Borge-Holthoefer J, Moreno Y (2014) Assessing the bias in samples of large online networks. Soc Networks 38:16-27. https://doi.org/10.1016/j.socnet.2014.01.004 
35. González-Ibánez R, Muresan S, Wacholder N (2011) Identifying sarcasm in twitter: a closer look. Proceedings of the 49th Annual Meeting of the Association for Computational Linguistics: Human Language Technologies, 2(1), 581-586. https://www.aclweb.org/anthology/P11-2102.pdf

36. Greene JC, Caracelli VJ, Graham WF (1989) Toward a conceptual framework for mixed-method evaluation designs. Educ Eval Policy Anal 11(3):255-274. https://doi.org/10.2307/1163620

37. Groves RM (2006) Nonresponse rates and nonresponse Bias in household surveys. Public Opin Q 70(5): 646-675. https://doi.org/10.1093/poq/nfl033

38. Groves RM, Lyberg L (2010) Total survey error: past, present, and future. Public Opin Q 74(5):849-879. https://doi.org/10.1093/poq/nfq065

39. Habermas J (1991) The structural transformation of the public sphere: an inquiry into a category of bourgeois society. MIT press, Cambridge

40. Harzing A-W (2007) Publish or Perish. https://harzing.com/resources/publish-or-perish. Accessed 1 March 2020

41. Hatipoğlu E, Gökçe OZ, Arin İ, Saygin Y (2019) Automated Text Analysis and International Relations: The Introduction and Application of a Novel Technique for Twitter. All Azimuth: A Journal of Foreign Policy and Peace 8(2):183-204. https://doi.org/10.20991/allazimuth.476852

42. Herbst S (1998) Reading public opinion: how political actors view the democratic process. University of Chicago Press, Chicago

43. Hsieh YP, Murphy J (2017) Total twitter error. In: Biemer PP, de Leeuw E, Eckman S, Edwards B, Kreuter F, Lyberg LE, Tucker NC, West BT (eds) Total survey error in practice. John Wiley \& Sons, Hoboken, NJ, pp 23-46

44. Jacobs K, Spierings N (2019) A populist paradise? Examining populists' twitter adoption and use. Inf Commun Soc 22(12):1681-1696. https://doi.org/10.1080/1369118X.2018.1449883

45. Japec L, Kreuter F, Berg M, Biemer P, Decker P, Lampe C, Lane J, O’Neil C, Usher A (2015) Big data in survey research: AAPOR task force report. Public Opin Q 79(4):839-880. https://doi.org/10.1093/poq/ nfv039

46. Johnson TP, Smith TW (2017) Big data and survey research: supplement or substitute? In: Thakuriah P, Tilahun N, Zellner M (eds) Seeing cities through big data: research, methods and applications in urban informatics. Springer, New York, pp 113-125

47. Jungherr A (2016) Twitter use in election campaigns: a systematic literature review. J Inform Technol Polit 13(1):72-91. https://doi.org/10.1080/19331681.2015.1132401

48. Karlsen R, Enjolras B (2016) Styles of social media campaigning and influence in a hybrid political communication system: linking candidate survey data with twitter data. Int J Press/Polit 21(3):338-357

49. Keeter S, Kennedy C, Clark A, Tompson T, Mokrzycki M (2007) What's Missing from National Landline RDD surveys?: the impact of the growing cell-only population. Public Opin Q 71(5):772-792. https://doi. org/10.1093/poq/nfm053

50. Kim D, Kim J (2014) Public opinion sensing and trend analysis on social media: a study on nuclear power on twitter. Int J Multimedia Ubiquitous Eng 9(11):373-384. https://doi.org/10.14257/ijmue.2014.9.11.36

51. Klašnja M, Barberá P, Beauchamp N, Nagler J, Tucker JA (2018) Measuring public opinion with social media data. In: Atkeson LR, Alvarez RM (eds) The Oxford handbook of polling and survey methods. Oxford University Press, Oxford, pp 555-582

52. Kreuter F, Presser S, Tourangeau R (2008) Social desirability Bias in CATI, IVR, and web surveys: the effects of mode and question sensitivity. Public Opin Q 72(5):847-865. https://doi.org/10.1093/poq/nfn063

53. Lee T (2002) Mobilizing public opinion: black insurgency and racial attitudes in the civil rights era. Chicago Univ. Press, Chicago

54. Loureiro ML, Alló M (2020) Sensing climate change and energy issues: sentiment and emotion analysis with social media in the U.K. and Spain. Energy Policy 143:111490. https://doi.org/10.1016/j.enpol.2020. 111490

55. Lukoianova T, Rubin VL (2013) Veracity roadmap: is big data objective, truthful and credible? Adv Classif Res Online 24(1):4-15. https://doi.org/10.7152/acro.v24i1.14671

56. McGregor SC (2019) Social media as public opinion: how journalists use social media to represent public opinion. Journalism 20(8):1070-1086. https://doi.org/10.1177/1464884919845458

57. Metzler K, Kim DA, Allum N, Denman A (2016) Who is doing computational social science? Trends in big data research. SAGE, London http://repository.essex.ac.uk/17679/1/compsocsci.pdf

58. Moy P, Murphy J (2016) Problems and prospects in survey research. J Mass Commun Q 9(1):16-37. https://doi.org/10.1177/1077699016631108

59. Murphy J, Dean E, Hill CA, Richards A (2011) Social media, new technologies, and the future of health survey research. Proceedings of the 10th conference on health survey research methods, 231-241. http:// www.srl.uic.edu/hsrm/hsrm 10 proceedings.pdf\#page $=236$ 
60. O’Connor B, Balasubramanyan R, Routledge BR, Smith NA (2010) From tweets to polls: linking text sentiment to public opinion time series. Proceedings of the 4th International AAAI Conference on Weblogs and Social Media, 4(1), 122-129. https://ojs.aaai.org/index.php/ICWSM/article/view/14031

61. Olteanu A, Castillo C, Diaz F, Kiciman E (2016) Social data: biases, methodological pitfalls, and ethical boundaries. Front Big Data 2(13):1-13. https://doi.org/10.3389/fdata.2019.00013

62. Park M, Park J, Baek YM, Macy M (2017) Cultural values and cross-cultural video consumption on YouTube. PLoS One 12(5):e0177865. https://doi.org/10.1371/journal.pone.0177865

63. Pavalanathan U, De Choudhury M (2015) Identity management and mental health discourse in social media. Proceedings of the 24th international conference on world wide web, 315-321. https://doi.org/10. $1145 / 2740908.2743049$

64. Plescia C, Kritzinger S, Sio LD (2019) Filling the void? Political responsiveness of populist parties. Representation 55(4):513-533. https://doi.org/10.1080/00344893.2019.1635197

65. Robillard JM, Whiteley L, Johnson TW, Lim J, Wasserman WW, Illes J (2013) Utilizing social media to study information-seeking and ethical issues in gene therapy. J Med Internet Res 15(3):e2313. https://doi. org/10.2196/jmir.2313

66. Rousidis D, Koukaras P, Tjortjis C (2020) Social media prediction: a literature review. Multimed Tools Appl 79:1-33. https://doi.org/10.1007/s11042-019-08291-9

67. Scarborough WJ (2018) Feminist twitter and gender attitudes: opportunities and limitations to using twitter in the study of public opinion. Socius 4:2378023118780760. https://doi.org/10.1177/2378023118780760

68. Schober MF, Pasek J, Guggenheim L, Lampe C, Conrad FG (2016) Social media analyses for social measurement. Public Opin Q 80(1):180-211. https://doi.org/10.1093/poq/nfv048

69. Schober MF, Conrad FG, Holzberg J, Ferg RA, Katz J, Childs JH, Beatty PC, Gagnon-Bartsch JA (2020) Better understanding when and how social media posts can augment public opinion surveys. Paper presented at the BigSurv20 big data meets survey science. https://www.bigsurv20.org/conf20/program/? sess $=11 \# 100$. Accessed 13 November 2020

70. Sen I, Floeck F, Weller K, Weiss B, Wagner C (2019) A Total Error Framework for Digital Traces of Humans. http://arxiv.org/abs/1907.08228. Accessed 1 June 2020

71. Shin J (2020) How do partisans consume news on social media? A comparison of self-reports with digital trace measures among twitter users. Soc Media Soc 6(4):1-12. https://doi.org/10.1177/2056305120981039

72. Stier S, Breuer J, Siegers P, Thorson K (2019) Integrating survey data and digital trace data: key issues in developing an emerging field. Soc Sci Comput Rev 38(5):0894439319843669. https://doi.org/10.1177/ 0894439319843669

73. Tavoschi L, Quattrone F, D’Andrea E, Ducange P, Vabanesi M, Marcelloni F, Lopalco PL (2020) Twitter as a sentinel tool to monitor public opinion on vaccination: an opinion mining analysis from September 2016 to august 2017 in Italy. Human Vaccines Immunother 16(5):1062-1069. https://doi.org/10.1080/ 21645515.2020.1714311

74. Thompson L, Rivara FP, Whitehill JM (2015) Prevalence of marijuana-related traffic on twitter, 20122013: a content analysis. Cyberpsychol Behav Soc Netw 18(6):311-319. https://doi.org/10.1089/cyber. 2014.0620

75. Tourangeau R, Galešić M (2008) Conceptions of attitudes and opinions. In: Donsbach W, Traugott MW (eds) The Sage Handbook of Public Opinion Research, London, London Sage Publications, pp 141-154

76. Trepte S, Reinecke L (2011) Privacy online: perspectives on privacy and self-disclosure in the social web. Springer-Verlag, Berlin Heidelberg. https://doi.org/10.1007/978-3-642-21521-6

77. Tufekci Z (2014) Big questions for social media big data: representativeness, validity and other methodological pitfalls. Proceedings of the $8^{\text {th }}$ International AAAI Conference on Web and Social Media, 8(1), 505-514. https://ojs.aaai.org/index.php/ICWSM/article/view/14517

78. Turow J, Hennessy M, Draper N (2015) The tradeoff fallacy: how marketers are misrepresenting American consumers and opening them up to exploitation. SSRN scholarly paper no. ID 2820060. Rochester, NY: social science research network. https://papers.ssrn.com/abstract=2820060. Accessed 1 June 2020

79. Vaccari C, Valeriani A, Barberá P, Jost JT, Nagler J, Tucker JA (2016) Of Echo chambers and contrarian clubs: exposure to political disagreement among German and Italian users of twitter. Soc Media Soc 2(3):124. https://doi.org/10.1177/2056305116664221

80. Varol O, Ferrara E, Davis CA, Menczer F, Flammini A (2017) Online human-bot interactions: detection, estimation, and characterization. Proceedings of the 11th International AAAI Conference on Web and Social Media, 11(1), 280-289. https://ojs.aaai.org/index.php/ICWSM/article/view/14871

Publisher's note Springer Nature remains neutral with regard to jurisdictional claims in published maps and institutional affiliations. 